\title{
Fiber-Reinforced Polymer-Packaged Optical Fiber Bragg Grating Strain Sensors for Infrastructures under Harsh Environment
}

\author{
Zhi Zhou, Zhenzhen Wang, and Lian Shao \\ Institute of Smart Structures, Dalian University of Technology, Ganjingzi, Liaoning, Dalian 116024, China \\ Correspondence should be addressed to Zhi Zhou; zhouzhi@dlut.edu.cn
}

Received 8 June 2016; Accepted 3 August 2016

Academic Editor: Rafael Morales

Copyright (C) 2016 Zhi Zhou et al. This is an open access article distributed under the Creative Commons Attribution License, which permits unrestricted use, distribution, and reproduction in any medium, provided the original work is properly cited.

Optical fiber Bragg grating (FBG) has been recognized as an outstanding high-performance local monitoring sensor and is largely applied in structural health monitoring (SHM). This paper proposes a series of fiber-reinforced polymer- (FRP-) packaged optical fiber Bragg grating strain sensors to completely meet the requirements of rough civil engineering infrastructures, and their sensing performance under normal environment and harsh environment is experimentally investigated. It is experimentally and theoretically proved that FRP-packaged FBG strain sensors maintain excellent sensing performance as the bare FBG sensor under a harsh environment, and their durability is significantly enhanced due to the FRP materials. These FRP-packaged FBG strain sensors are successfully applied in the SHM system of Aizhai Bridge.

\section{Introduction}

Infrastructures, such as long-span bridges, high-rise buildings, large dams, nuclear power stations, and offshore platforms, will inevitably suffer damage accumulation and resistance degradation subjected to coupling actions of environmental corrosion, material aging, long-term loading, fatigue, and natural disaster hazards, even collapse, during their long time of service [1]. Therefore, in order to assure structural safety, integrity, suitability, and durability, a lot of infrastructures in service are in great need for intelligent health monitoring systems to evaluate their safety and rehabilitate and further control their damage. Due to the frequent disastrous lessons, more and more infrastructures have been equipped with long-term health monitoring systems during construction [2]. As one of the most important inventions in the measurement field in the late 20th century, optical fiber Bragg grating (FBG) has been greatly recognized and largely applied in long-term structural health monitoring (SHM) due to the fact that optical FBG shows distinguishing advantages: electromagnetic resistance, small size, resistance to corrosion, and so forth [3-11]. Fiber Bragg grating sensors further provide an absolute measurement that exhibits minimal drift with time, which performs measurement at a discrete position in the fiber, and several sensors can be multiplexed for a complex network connected to a single interrogator along a single fiber. As the main ingredient of the bare optical fiber is $\mathrm{SiO}_{2}$ and the outer diameter is only $125 \mu \mathrm{m}$, the shear capacity of the optical fiber is so poor. Due to its fragility, it is rather difficult to be applied directly in the rough civil engineering infrastructures and harsh environments without packaging. Therefore, it is an important issue to develop packaging techniques for bare FBG strain sensors, which can be well protected inside the matrix component and less likely to be damaged by external infringement. The key problem of this development focuses on the selection of packaging materials for sensors form of different layout process and performance requirements, in order to ensure the that packaged FBG sensor possesses excellent durability, linearity, repeatability, and measurement range for long-term monitoring of civil engineering. There are three solutions for realizing the combination of FBG sensors and packaging materials. Firstly, metallic materials can be chosen as the packaging materials to combine with FBG sensors by an adhesive interlayer. Because of the plastic properties under large strain conditions and corrosion of metallic materials, as well as the creep and aging characteristics of the adhesive interlayer, sensors developed by this encapsulation technique are deficient in durability, linearity, and repeatability, in addition to the small measurement scale (less than $2000 \mu \varepsilon$ ). 
Secondly, the FBG sensors are firstly clamped with the ended mechanical anchorage and then packaged by the additional protection. It is inevitable that the creep of OFBG sensors would occur under sustained loads due to mechanical clamping; therefore, the measurement scale is just as the ultimate strain of the FBG sensor. In addition to this, the durability is restricted by the material of the clamping devices. Thirdly, advanced composites can be introduced as packaging materials, such as fiber-reinforced polymer (FRP), including carbon fiber-reinforced polymer (CFRP), aramid fiber-reinforced polymer (AFRP), basalt fiber-reinforced polymer (BFRP), and glass fiber-reinforced polymer (GFRP). FRP composites are originated from the design of large, high-performance structures in the aerospace industry. A fundamental issue in the implementation of an OFBG-based SHM system in composite structures aerospace area is the embedment of sensors during manufacturing. Tsutsui et al. applied smalldiameter optical fiber sensors to stiffened composite panels for the detection of impact damage [12]. Ryu et al. have used multiplexed and multichanneled built-in FBG sensors to monitor the buckling behavior of a composite wing box [13]. Takeda et al. used FBG sensors to monitor damage due to compressive load in CFRP stiffened panels [14]. Tserpes et al. developed an integrated methodology for monitoring strain and damage in CFRP fuselage panels, and embedment of fiber sensors in the panel during manufacturing was done so as to minimize risk of fiber breaking during manufacturing and impact testing and to effectively capture strains being representative of the damage developed in the panel [15].

In this paper, the bonding mechanism of the combination of FRP and FBG sensors is explored firstly. And then an experiment program is conducted for investigating the durability properties of BFRP bars and GFRP bars, which are used as typical encapsulation materials. Thirdly, series of FRP-packaged FBG strain sensors are developed for infrastructures under harsh environment, and their sensing performance under normal environment and harsh environment is experimentally investigated. Finally, the practical application of these FRP-packaged FBG strain sensors in Aizhai Bridge SHM system is briefly introduced.

\section{Bonding Mechanism between FRP and FBG Sensors}

As we know, the sensing properties of FRP-packaged optical fiber strain sensors are determined by the FBG and packaging materials. Due to the small proportion of FBG, the basic sensing performance properties, such as linearity, repeatability, and measurement scale, and the main durability index are directly influenced by the basic mechanical and chemical properties of packaging materials. Fiber-reinforced polymer composites provide a reliable means for the development of high-performance packaged optical fiber strain sensors, owing to their linear-elastic material constitutive properties, namely, the notion that the elastic modulus remains constant until failure (as shown in Figure 1), excellent fatigue performance, and durability. Particularly for that, the wholeprocess pseudoelasticity of FRP composites ensures the perfect linearity and repeatability of the FRP-packaged optical

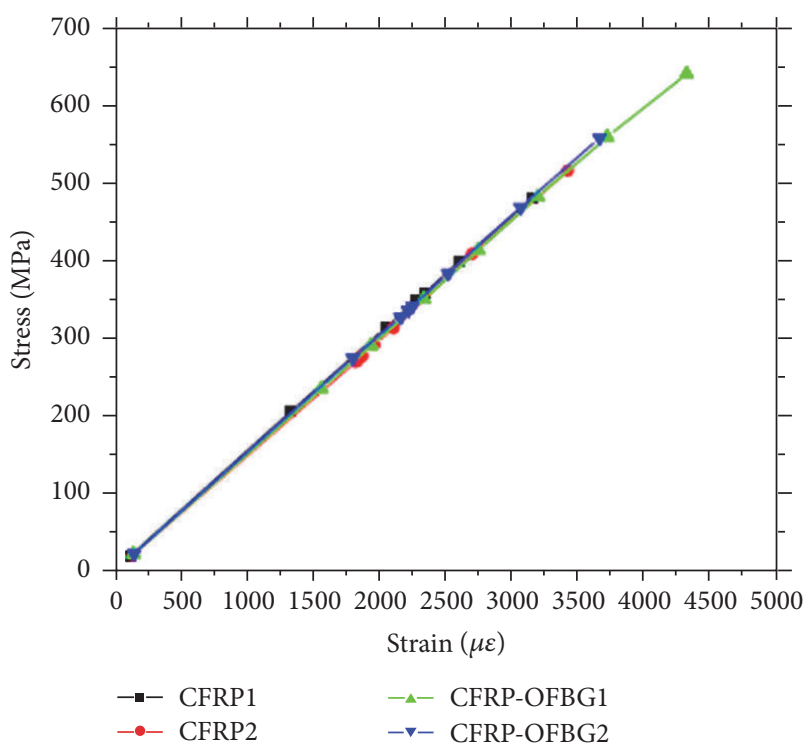

FIGURE 1: The constitutive curve of CFRP bar.

fiber strain sensors in the whole measurement scale. The fundamental basis of taking FRP composites as packaging materials is further explained as follows.

\subsection{The Compatibility between FBG and FRP Composites.} From the point of view of material component, fiberreinforced polymer composites commonly consist of glass fibers (or carbon fibers, aramid fibers, basalt fiber, and hybrid fiber), resins, additives, and so forth. Silica, as the basic composition of the optical fiber, is also the main material composition of glass fibers. Thus, the glass fibers are infiltrated in the resin and cure for molding easily, which is the same as optical fibers. It is shown from the SEM photo (Figure 2) of bare FBG and FRP that the bare fiber FRP combined well with FRP composites and worked together in the manner of full interaction.

\subsection{Effect of FRP on the Sensing Characteristics of FBG Sensors.} The main indexes of sensing elements are highlighted in linearity, measurement range, repeatability, and so forth, and the macroscopic constitutive property of FRP materials is just linear elastic, which ensures that the excellent linearity of the FBG sensor would be maintained after encapsulating. In addition to that, the FBG is precompressed and induced by the shrinkage of the resin in the curing process of thermosetting FRP composites, due to their perfect bonding with FRP composites, and the precompressed section will be the extended portion for the tensile strain measurement range, compared with the bare FBG sensor under the initially unstressed state. According to the experiment results shown in Figure 3, the range of GFRP-packaged FBG sensor can reach up to $7000 \sim 8000 \mu \varepsilon$. By contrast, the range of bare FBG sensors is only $3000 \sim 4000 \mu \varepsilon$. Thus, it can be seen that FRP composites increase the measurement scale significantly without changing the sensing performance of the FBG sensor (Figure 5). 


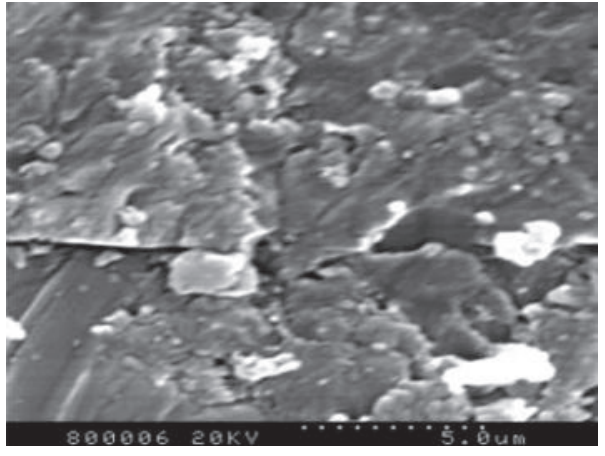

(a) The interface of bare FBG and CFRP

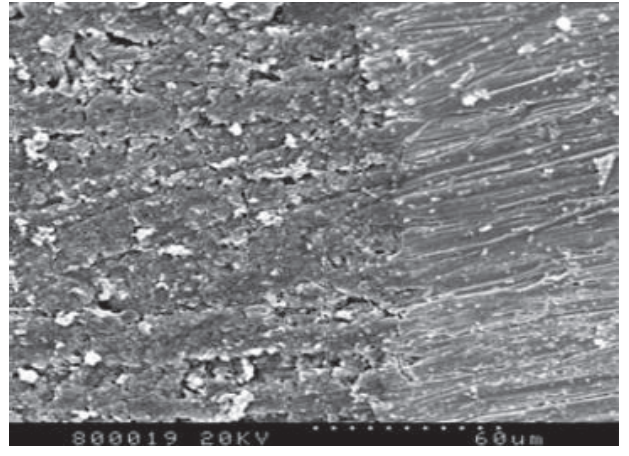

(b) The interface of bare FBG and CFRP

FIgURE 2: SEM photo of bare FBG and FRP.

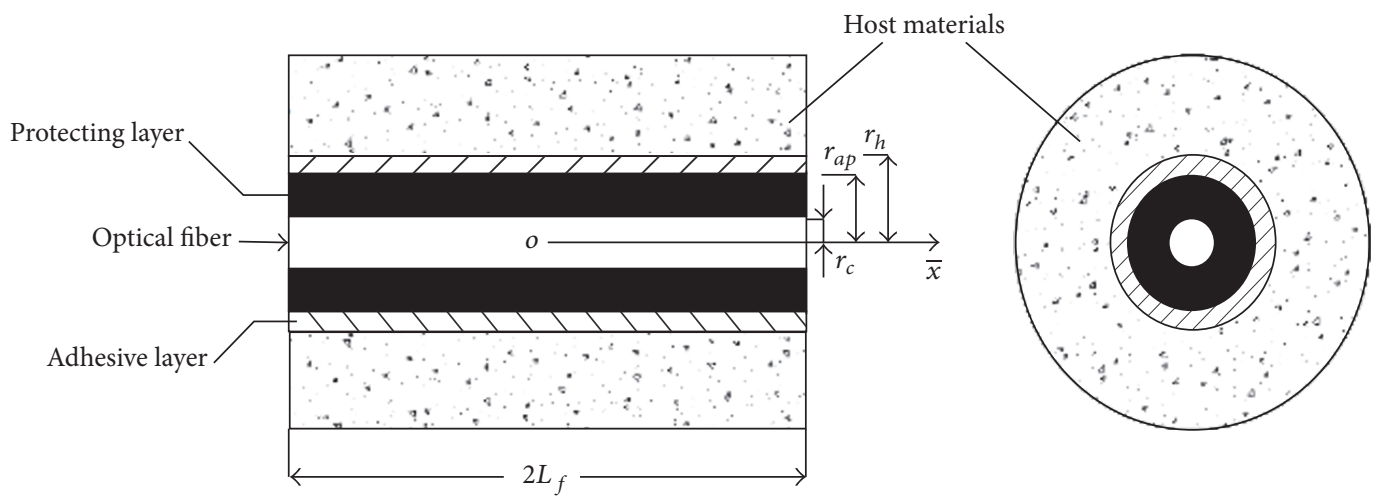

(a)

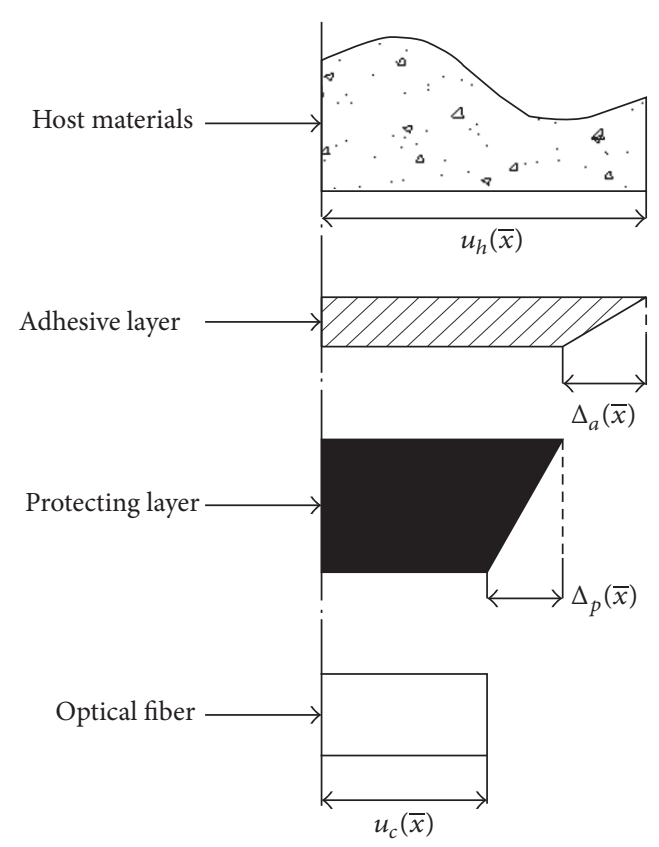

(b)

FIGURE 3: Cylindrical model of optical fiber strain sensing and relationship of deformation. 
2.3. Strain Transfer of the FRP-Packaged Optical Fiber Strain Sensors. Embedded FRP-packaged FBG sensors are usually constituted by FRP encapsulation layer and sensing fiber. Deformation of host materials induced by external action passes through FRP encapsulation layer at first and then arrives at the FBG sensor, with a part of strain consumed by the FRP encapsulation layer in the strain transferring process, which causes the strain transfer error between the target strain of structures $\varepsilon_{h}(0)$ and measurement of FBG sensors $\varepsilon_{c}(\bar{x})$. In order to estimate the error between the measurement of FBG sensors and the strain of structures, as well as correcting the strain transfer error and improving the testing accuracy of sensors, a cylinder within the effective working length of optical fibers consisting of optical fiber, protecting layer, adhesive layer, and host materials was chosen as the mechanical analysis model to investigate the strain transfer mechanism in optical fiber sensing. Basic assumptions were introduced as follows: (1) optical fiber, protecting layer, adhesive layer, and host materials were considered to be linear elastic and isotropic; (2) all of the adhesive interfaces were continuous and satisfied the deformation compatibility condition; (3) temperature effects were ignored; (4) optical fiber is not sensitive to lateral stress, and thus the lateral stress and shear stress were ignored. According to the hypothesis of displacement continuity, the displacement at arbitrary point in the cylindrical model can be expressed as in the following formula:

$$
u(\bar{x})= \begin{cases}u_{c}(\bar{x}) & 0 \leq r \leq r_{c} \\ u_{p}(r, \bar{x}) & r_{c}<r \leq r_{a p} \\ u_{a}(r, \bar{x}) & r_{a p}<r \leq r_{h} \\ u_{h}(\bar{x}) & r>r_{h} .\end{cases}
$$

In formula $(1), u_{c}(\bar{x}), u_{p}(r, \bar{x}), u_{a}(r, \bar{x})$, and $u_{h}(\bar{x})$ are represented as the displacement of the optical fiber, protecting layer, adhesive layer, and host materials, respectively. The displacement compatibility equations at the adhesive interface are shown in formula (2). Due to the presence of the protective layer and adhesive layer, there is relative displacement between the optical fiber and host materials, which is induced by the shear deformation of the protective layer and the adhesive layer. The quantity relationships between the relative displacement for the optical fiber and host materials and shear deformation in the protective layer and the adhesive layer are given in formulas (3) (5). The relative displacement at each interface is shown in Figure 3(b). Hence,

$$
\begin{aligned}
u_{c}(\bar{x}) & =u_{p}\left(r_{c}, \bar{x}\right) \\
u_{p}\left(r_{c}, \bar{x}\right) & =u_{a}\left(r_{c}, \bar{x}\right) \\
u_{a}\left(r_{c}, \bar{x}\right) & =u_{h}(\bar{x}) \\
u_{h}(\bar{x})-u_{c}(\bar{x}) & =\Delta_{a}(\bar{x})+\Delta_{p}(\bar{x}) \\
u_{a}\left(r_{h}, \bar{x}\right)-u_{a}\left(r_{a p}, \bar{x}\right) & =\Delta_{a}(\bar{x}) \\
u_{p}\left(r_{a p}, \bar{x}\right)-u_{p}\left(r_{c}, \bar{x}\right) & =\Delta_{p}(\bar{x}) .
\end{aligned}
$$

When $\bar{x}=0$,

$$
\varepsilon_{c}(r, 0)=\varepsilon_{a}(r, 0)=\varepsilon_{a p}(r, 0)=\varepsilon_{h}(r, 0)
$$

The axial force equilibria for the optical fiber infinitesimal, protecting layer infinitesimal, and adhesive layer infinitesimal are shown in Figures 4(a)-4(c), and the axial force equilibrium equations are

$$
\begin{aligned}
\sum F_{\bar{x}} & =0 \\
\frac{d \sigma_{c}(\bar{x})}{d \bar{x}} & =-\frac{2 \tau_{p c}\left(r_{c}, \bar{x}\right)}{r_{c}} \\
\frac{d \sigma_{p}(\bar{x})}{d \bar{x}} & =\frac{2\left[\tau_{p c}\left(r_{c}, \bar{x}\right) r_{c}-\tau_{a p}\left(r_{a p}, \bar{x}\right) r_{a p}\right]}{r_{a p}^{2}-r_{c}^{2}} \\
\frac{d \sigma_{a}(\bar{x})}{d \bar{x}} & =\frac{2\left[\tau_{a p}\left(r_{a p}, \bar{x}\right) r_{c}-\tau_{h}\left(r_{h}, \bar{x}\right) r_{h}\right]}{r_{h}^{2}-r_{a p}^{2}} .
\end{aligned}
$$

Deformation compatibility equations in the protective layer and adhesive layer can be approximately expressed as [16]

$$
\begin{aligned}
& \tau(r, \bar{x})=\frac{r_{a p}}{r} \tau_{a p}\left(r_{a p}, \bar{x}\right) \quad r_{c} \leq r \leq r_{a p} \\
& \tau(r, \bar{x})=\frac{r_{h}}{r} \tau_{h}\left(r_{h}, \bar{x}\right) \quad r_{a p} \leq r \leq r_{h} .
\end{aligned}
$$

When $r=r_{c}$ and $r=r_{a p}$,

$$
\begin{aligned}
& \frac{d \sigma_{p}(\bar{x})}{d \bar{x}}=0, \\
& \frac{d \sigma_{a}(\bar{x})}{d \bar{x}}=0 .
\end{aligned}
$$

Therefore,

$$
\begin{aligned}
\sigma_{p}(\bar{x}) & =\text { cons } \tan t \\
\sigma_{a}(\bar{x}) & =\text { cons } \tan t .
\end{aligned}
$$

Physical equations and geometric equations for optical fiber, protecting layer, and adhesive layer are as follows:

$$
\begin{aligned}
\varepsilon_{h}(\bar{x}) & =\frac{\sigma_{h}(\bar{x})}{E_{h}} \\
\varepsilon_{c}(\bar{x}) & =\frac{\sigma_{c}(\bar{x})}{E_{c}} \\
\gamma_{a}(r, \bar{x}) & =\frac{\tau(r, \bar{x})}{G_{a}} \quad r_{a p} \leq r \leq r_{h} \\
\gamma_{p}(r, \bar{x}) & =\frac{\tau(r, \bar{x})}{G_{p}} \quad r_{c} \leq r \leq r_{a p} .
\end{aligned}
$$




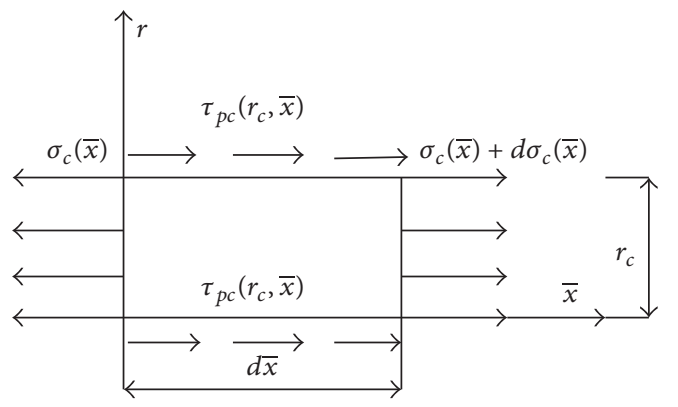

(a) FBG

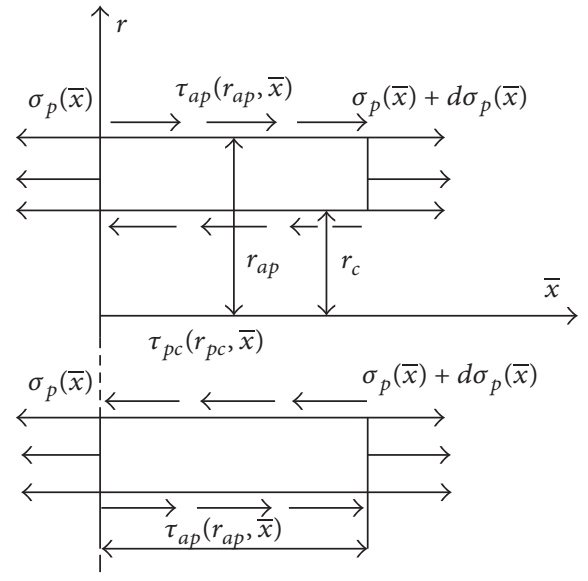

(b) Protecting layer

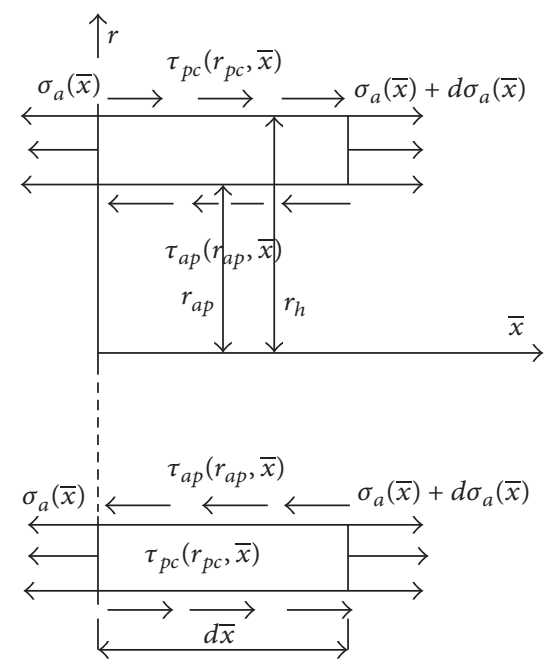

(c) Adhesive layer

FIGURE 4: Schematic diagram of an infinitesimal.

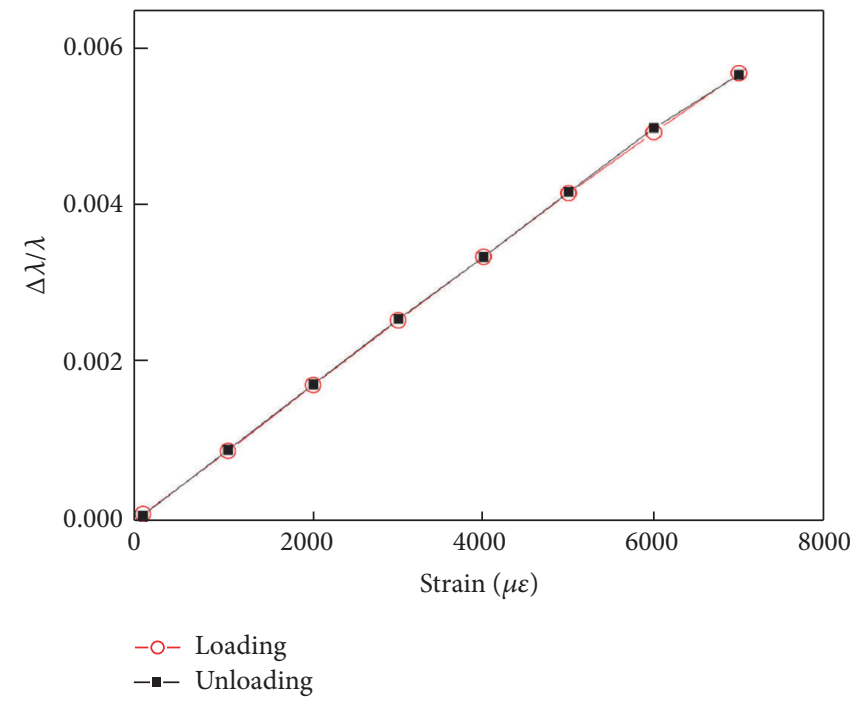

(a) The strain sensing sensitivity of OFBG-GFRP bars

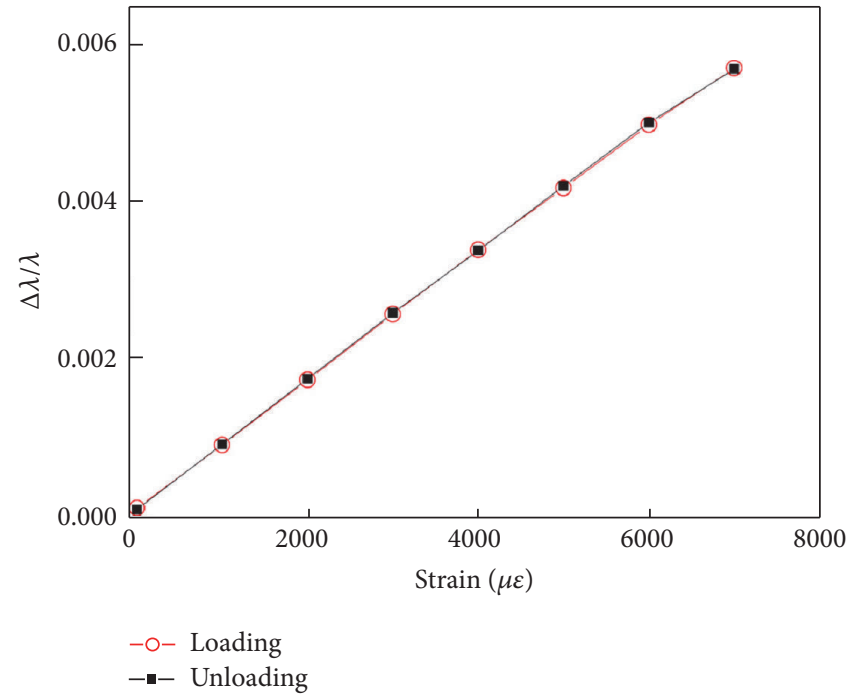

(b) The range and repeatability of OFBG-GFRP bars

FIgURE 5: The effect of FRP on FBG. 
Therefore,

$$
\begin{aligned}
& u_{h}(\bar{x})=\int_{0}^{\bar{x}} \varepsilon_{h}(\bar{x}) d \bar{x}=\int_{0}^{\bar{x}} \frac{\sigma_{h}(\bar{x})}{E_{h}} d \bar{x} \\
& u_{c}(\bar{x})=\int_{0}^{\bar{x}} \varepsilon_{c}(\bar{x}) d \bar{x}=\int_{0}^{\bar{x}} \frac{\sigma_{c}(\bar{x})}{E_{c}} d \bar{x} \\
& \Delta_{a}(\bar{x})=\int_{r_{a p}}^{r_{h}} \gamma_{a}(r, \bar{x}) d r=\frac{1}{G_{a}} \int_{r_{a p}}^{r_{h}} \tau_{a}(r, \bar{x}) d r \\
& \Delta_{p}(\bar{x})=\int_{r_{c}}^{r_{a p}} \gamma_{p}(r, \bar{x}) d r=\frac{1}{G_{a}} \int_{r_{c}}^{r_{a p}} \tau_{a}(r, \bar{x}) d r .
\end{aligned}
$$

Formula (16) can be derived by means of substituting formulas (11) and (15) into formula (3), whose first derivative and second derivative are shown in formulas (17) and (18), respectively. The differential equation of interfacial shear stress $\tau_{a p}\left(r_{a p}, \bar{x}\right)$ in formula (18) is obtained based on formula (8) and the assumption that the axial stress of host materials $\sigma_{h}(\bar{x})$ is considered to be constant in case of short measured length.

$$
\begin{aligned}
& \int_{0}^{\bar{x}} \frac{\sigma_{h}(\bar{x})}{E_{h}} d \bar{x} \\
& \quad=r_{a p} \tau_{a p}\left(r_{a p}, \bar{x}\right)\left[\frac{1}{G_{a}} \ln \frac{r_{h}}{r_{a p}}+\frac{1}{G_{p}} \ln \frac{r_{a p}}{r_{c}}\right] \\
& \quad+\int_{0}^{\bar{x}} \frac{\sigma_{c}(\bar{x})}{E_{c}} d \bar{x} \\
& \frac{\sigma_{h}(\bar{x})}{E_{h}}=r_{a p}\left[\frac{1}{G_{a}} \ln \frac{r_{h}}{r_{a p}}+\frac{1}{G_{p}} \ln \frac{r_{a p}}{r_{c}}\right] \frac{\partial \tau_{a p}\left(r_{a p}, \bar{x}\right)}{\partial \bar{x}} \\
& \quad+\frac{\sigma_{c}(\bar{x})}{E_{c}} \\
& {\left[\frac{1}{G_{a}} \ln \frac{r_{h}}{r_{a p}}+\frac{1}{G_{p}} \ln \frac{r_{a p}}{r_{c}}\right] \frac{\partial \tau_{a p}^{2}\left(r_{a p}, \bar{x}\right)}{\partial^{2} \bar{x}}} \\
& \quad-\frac{2}{E_{c} r_{c}^{2}} \tau_{a p}\left(r_{a p}, \bar{x}\right)=0,
\end{aligned}
$$

where

$$
\lambda_{1}^{2}=\frac{2}{E_{c} r_{c}^{2}\left[\left(1 / G_{a}\right) \ln \left(r_{h} / r_{a p}\right)+\left(1 / G_{p}\right) \ln \left(r_{a p} / r_{c}\right)\right]} .
$$

Therefore, formula (18) can be simplified as

$$
\frac{\partial \tau_{a p}^{2}\left(r_{a p}, \bar{x}\right)}{\partial^{2} \bar{x}}-\lambda_{1}^{2} \tau_{a p}\left(r_{a p}, \bar{x}\right)=0 .
$$

The general solution is obtained as follows:

$$
\tau_{a p}\left(r_{a p}, \bar{x}\right)=A \cosh \left(\lambda_{1} \bar{x}\right)+B \sinh \left(\lambda_{1} \bar{x}\right) .
$$

The axial force of the optical fiber can be expressed as follows:

$$
N_{c}(\bar{x})=\int_{A} \sigma_{c}(\bar{x}) d x,
$$

noting that $\sigma_{c}(0)=\sigma_{c}$.
And then,

$$
\sigma_{c}(\bar{x})=\sigma_{c}-\frac{2 r_{a p}}{r_{c}^{2}} \int_{0}^{\bar{x}} \tau_{a p}\left(r_{a p}, \bar{x}\right) d \bar{x} .
$$

Therefore,

$$
N_{c}(\bar{x})=\pi r_{c}^{2} \sigma_{c}-2 \pi r_{a p} \int_{0}^{\bar{x}} \tau_{a p}\left(r_{a p}, \bar{x}\right) d \bar{x} .
$$

Introducing formula (21) into formula (24), the axial force of the optical fiber can be expressed in the following:

$$
\begin{aligned}
N_{c}(\bar{x})= & \pi r_{c}^{2} \sigma_{c} \\
& -2 \pi r_{a p} \frac{1}{\lambda}[A \operatorname{sh}(\lambda \bar{x})+B \operatorname{ch}(\lambda \bar{x})+B] .
\end{aligned}
$$

On the basis of formula (6) and the axial force of the optical fiber being zero at $\bar{x}=l_{f}$, the following boundary conditions are introduced to calculate integration constants $A$ and $B$ :

$$
\begin{aligned}
N_{c}(0) & =\sigma_{h} \pi r_{c}^{2} \frac{E_{c}}{E_{h}} \\
N_{c}\left(l_{f}\right) & =0 \\
A & =\frac{\sigma_{c} r_{c}^{2} \lambda}{2 r_{a p} \operatorname{sh}\left(\lambda l_{f}\right)}, \\
B & =0 .
\end{aligned}
$$

Thus, the interfacial shear stress can be obtained as follows:

$$
\begin{aligned}
\tau_{a p}\left(r_{a p}, \bar{x}\right) & =\frac{\sigma_{c} r_{c}^{2} \lambda}{2 r_{a p} \operatorname{sh}\left(\lambda l_{f}\right)} \operatorname{ch}\left(\lambda l_{f}\right) \\
\varepsilon_{c}(\bar{x}) & =\varepsilon_{c}(0) \times\left[1-\frac{\operatorname{sh}(\lambda \bar{x})}{\operatorname{sh}\left(\lambda l_{f}\right)}\right] \\
& =\varepsilon_{h}(0) \times\left[1-\frac{\operatorname{sh}(\lambda \bar{x})}{\operatorname{sh}\left(\lambda l_{f}\right)}\right] .
\end{aligned}
$$

In (28), $\varepsilon_{h}(0)$ is the axial strain of the host material at $\bar{x}=0$.

This is the generic expression of strain transfer mechanism for the embedded optical fiber sensors; as for embedded FRP-OFBG strain sensors, adjustments shown as follows should be made with specific application $r_{a p} \rightarrow r_{c}, G_{a} \rightarrow$ $G_{\mathrm{FRP}}$; therefore, formula (19) is converted to the following formula:

$$
\lambda_{1}^{2}=\frac{2 G_{\mathrm{FRP}}}{E_{c} r_{c}^{2} \ln \left(r_{h} / r_{c}\right)} .
$$

We defined the average strain measurement of FBG sensors $\bar{\varepsilon}_{c}(\bar{x})$ and the average strain of structures $\bar{\varepsilon}_{h}(\bar{x})$. The interfacial 
TABLE 1: Interlaminar shear strength of BFRP and GFRP rebar under salt and acid condition under different age.

\begin{tabular}{|c|c|c|c|c|}
\hline FRP bars & Corrosion solution & Items & 20 days & 240 days \\
\hline \multirow{8}{*}{ BFRP } & \multirow{3}{*}{ Salt } & Average value & 45.1 & 31.2 \\
\hline & & Variance & 2.2 & 2.5 \\
\hline & & Deterioration rate & -9.8 & -37.6 \\
\hline & \multirow{3}{*}{ Acid } & Average value & 43.3 & 29.4 \\
\hline & & Variance & 2.4 & 3.3 \\
\hline & & Deterioration rate & -13.4 & -41.2 \\
\hline & \multirow{2}{*}{ Blank specimen } & Interlaminar shear strength (MPa) & \multicolumn{2}{|c|}{50} \\
\hline & & Variance (MPa) & \multicolumn{2}{|c|}{1.5} \\
\hline \multirow{8}{*}{ GFRP } & \multirow{3}{*}{ Salt } & Average value & 48.2 & 39.6 \\
\hline & & Variance & 1.8 & 2.5 \\
\hline & & Deterioration rate & -6.2 & -23 \\
\hline & \multirow{3}{*}{ Acid } & Average value & 46.8 & 37.9 \\
\hline & & Variance & 2.1 & 3.2 \\
\hline & & Deterioration rate & -8.9 & -26.3 \\
\hline & \multirow{2}{*}{ Blank specimen } & Interlaminar shear strength (MPa) & & \\
\hline & & Variance $(\mathrm{MPa})$ & & \\
\hline
\end{tabular}

strain transferring error rate $\eta$ and the error correction factor $k$ are expressed as follows:

$$
\begin{aligned}
\bar{\varepsilon}_{c}(\bar{x}) & =\frac{\int_{0}^{l_{f}} \varepsilon_{c}(\bar{x}) d \bar{x}}{L_{f}} \\
\bar{\varepsilon}_{h}(\bar{x}) & =\frac{\int_{0}^{l_{f}} \varepsilon_{h}(\bar{x}) d \bar{x}}{L_{f}} \\
\eta & =\frac{\left|\bar{\varepsilon}_{c}(\bar{x})-\bar{\varepsilon}_{h}(\bar{x})\right|}{\bar{\varepsilon}_{h}(\bar{x})}=\frac{\cosh \left(\lambda_{1} L_{f}\right)-1}{\lambda_{1} L_{f} \sinh \left(\lambda_{1} L_{f}\right)} \\
k & =\frac{1}{1-\eta} .
\end{aligned}
$$

In (29), $G_{\mathrm{FRP}}$ is the shear modulus of the FRP composites; $E_{c}$ is the elastic modulus of the optical FBG; $r_{h}$ is the distance between optical fiber and matrix material; $r_{c}$ is the outer diameter of the optical fiber; $2 L_{f}$ is the effective working length of the optical fiber.

Calculations proved that the interfacial strain transferring error rate of CFRP-OFBG bars for the shear modulus being greater than $12 \mathrm{GPa}$ and the outer diameter being $\Phi 4 \sim$ $\Phi 10 \mathrm{~mm}$ is $1.92 \sim 2.16 \%$, and the corresponding error correction factor $k$ is $1.02 \sim 1.022$. By contrast, the interfacial strain transferring error rate of GFRP-OFBG bars for the shear modulus being greater than $4.9 \mathrm{GPa}$ and the outer diameter being $\Phi 4 \sim \Phi 10 \mathrm{~mm}$ is 3.11 3.5\%, and the corresponding error correction factor $k$ is $1.034 \sim 1.036$. From the results provided in this section, we can conclude that the test accuracy of FRP-packaged optical fiber strain sensors is sufficient for civil engineering structures with significant material discrete characteristic and can be applied in the practical structures directly without any error correction.

\section{Corrosion Durability Test of the FRP Bars}

Corrosion durability tests of the GFRP bars and BFRP bars under the condition of acid and alkali salt were conducted in this section, with the comparative study of degeneration of interlaminar shear properties and tensile properties after corrosion. The corrosion solution with different ingredient and mixing ratio was exploited to simulate the acid, alkali, and salt corrosion environment in the practical civil engineering.

3.1. Variation in Tensile Properties of FRP Bars. The ultimate tensile strength and tensile modulus of the BFRP bars and GFRP bars after being corroded in the acid, alkali, and salt solution for 20 days and 240 days are summarized in Table 1 .

The variations of the ultimate tensile strength and tensile modulus of the BFRP bars and GFRP bars with corrosive time are presented in Figures 6 and 7. Since BFRP bars were severely damaged in the alkali solution in 20 days, the tensile strength of both FRP bars was not measured due to the lack of a control group. It is shown that both of the ultimate tensile strengths increase with the corrosive time in the acid and salt solution. For a particular corrosive time, loss of the ultimate tensile strength of BFRP bars is more than that of GFRP bars in either acid solution or salt solution; besides, loss of the ultimate tensile strength in the acid solution is more than in the salt solution for both of the FRP bars. Whereas the tensile modulus of BFRP bars increases with the corrosive time, on the contrary, the tensile modulus of GFRP bars decreases with the corrosive time. In addition to that, the change rate of the tensile modulus for both FRP bars in the acid solution is more than that in the salt solution. Although the corrosion damage of basalt fibers does not occur, the interface between fibers and the resin is corrosively damaged by the acid solution and the salt solution, which cannot transfer the tension stress between fibers effectively, inducing stress concentration in a portion of fibers, followed by the decrease of ultimate tensile 


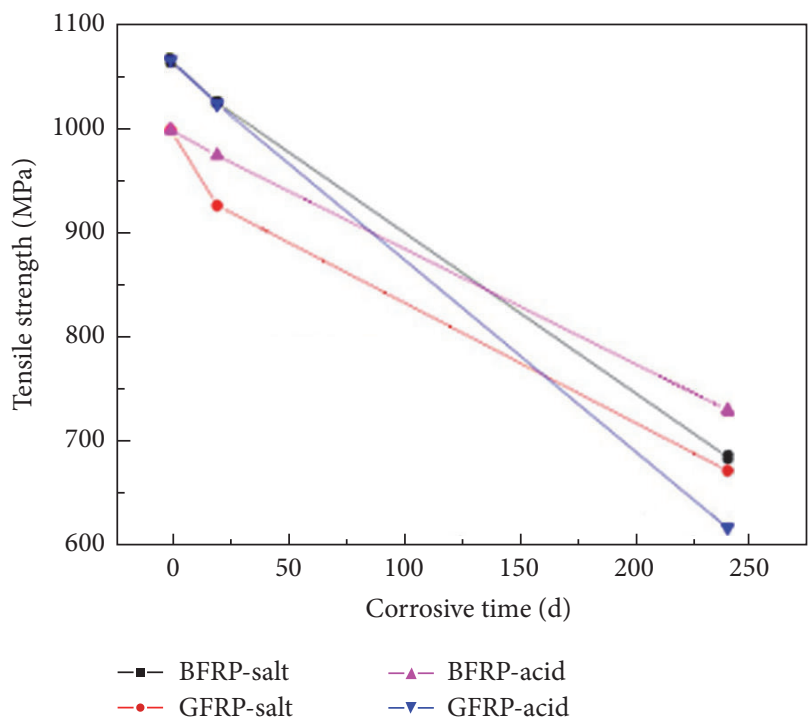

(a)

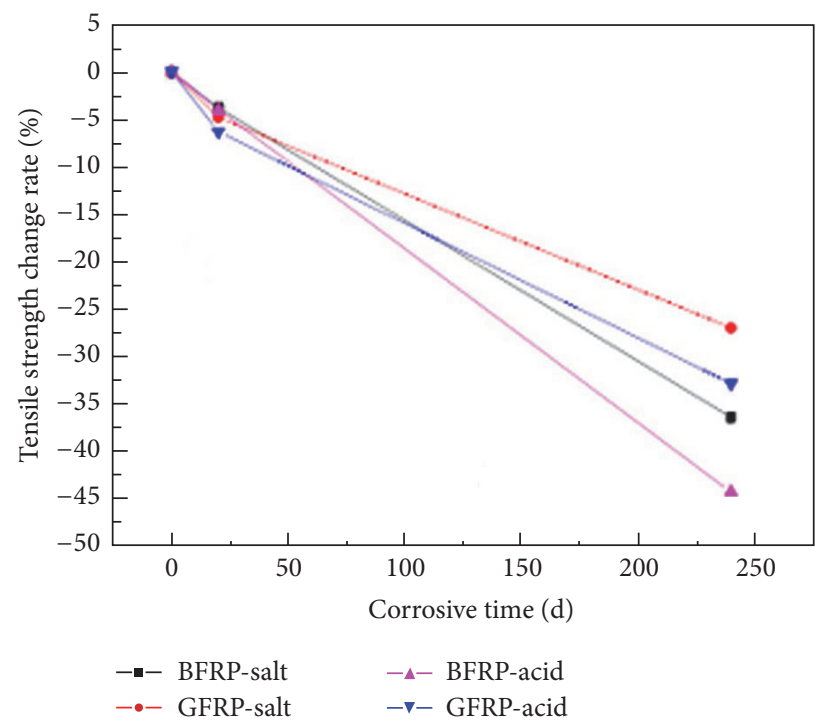

(b)

FIGURE 6: Curves of tensile strength versus age of BFRP and GFRP rebar under acid and salt condition.

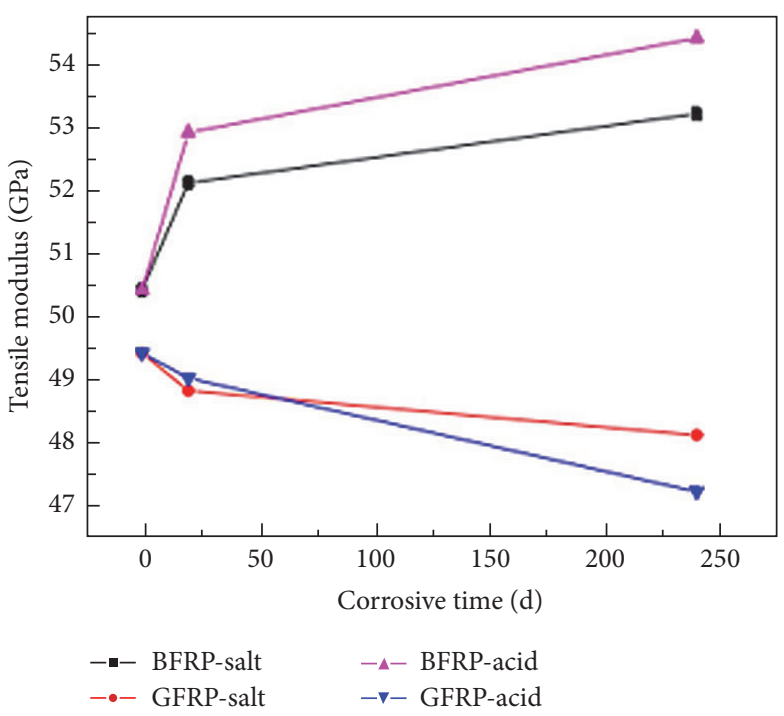

(a)

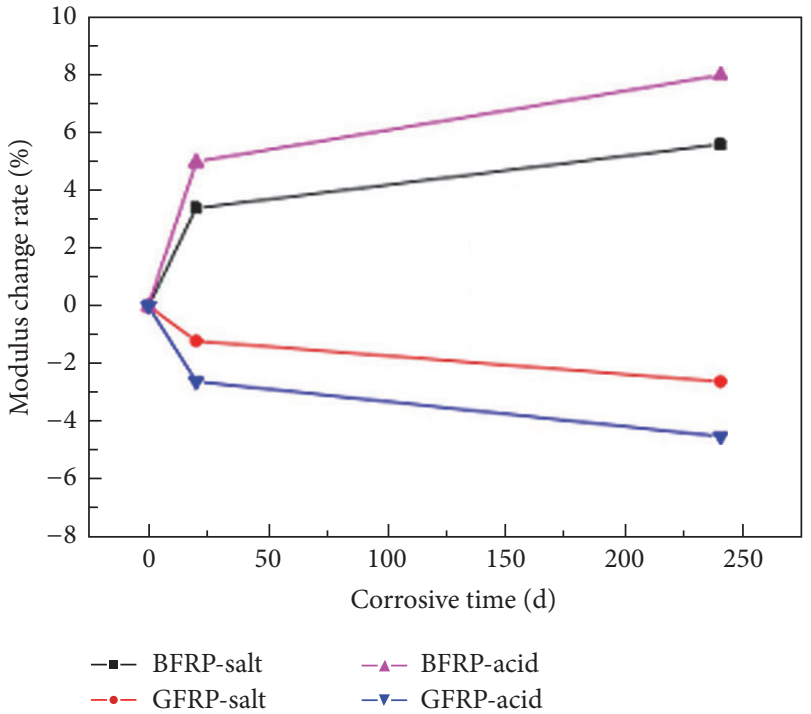

(b)

FIGURE 7: Curves of tensile modulus versus age of BFRP and GFRP rebar under acid and salt condition.

strength of BFRP bars. In addition, the relative slip between fibers and resin is also induced by the deterioration of the adhesive interface.

3.2. Variation in Interlaminar Shear Strength of FRP Bars. The interlaminar shear strength of BFRP and GFRP rebar under salt and acid condition under different age is summarized in Table 1.

The interlaminar shear strength of FRP bars is the important parameter reflecting the bonding properties between the resin and the fibers throughout the short beam shear test.
The interlaminar shear strength of BFRP bars and GFRP bars decreases with corrosive time, and degeneration of the interlaminar shear strength for both FRP bars in the acid solution is more than that in the salt solution. In addition, loss of the interlaminar shear strength of BFRP bars is more than in the GFRP bars in both acid solution and salt solution. The variation of interlaminar shear strength mentioned above reveals the deterioration of the adhesive interface between fibers and the resin induced by the corrosive solution, as shown in Figure 8. 


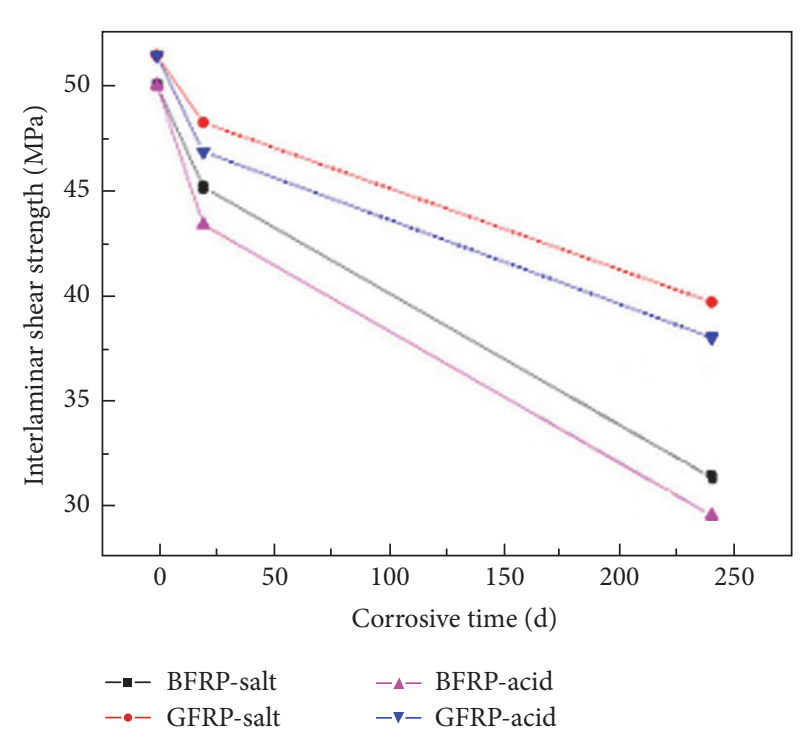

(a)

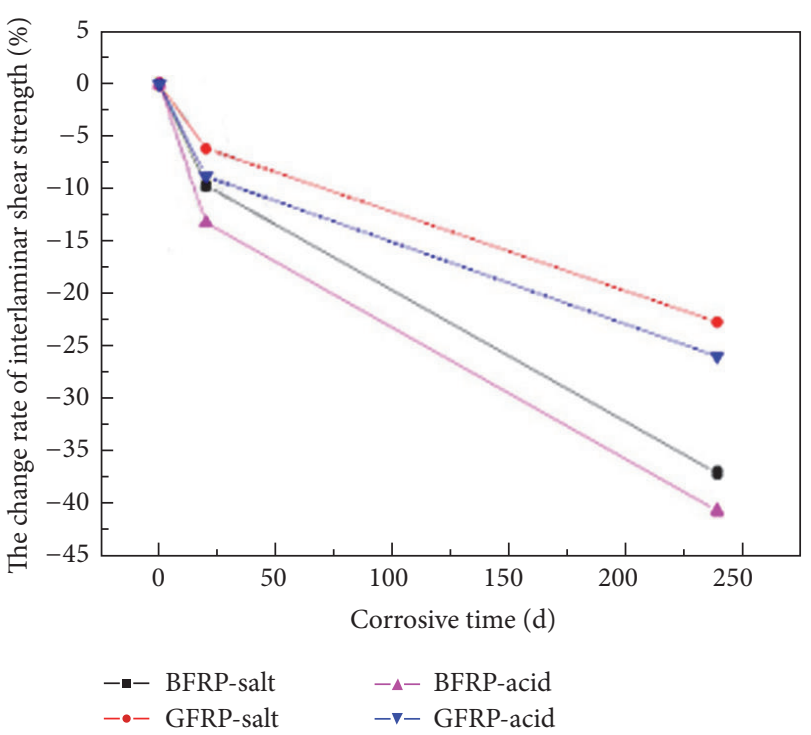

(b)

FIGURE 8: Curves of interlaminar shear strength and age in BFRP and GFRP rebar under acid and salt condition.
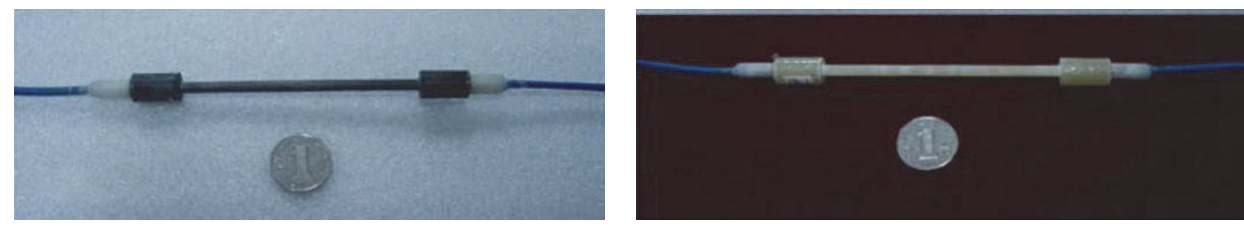

FIGURE 9: Embeddable FRP-FBG strain sensor.
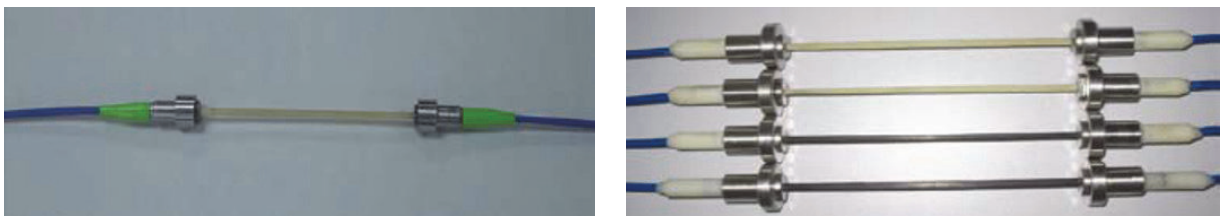

FIGURE 10: Embeddable FRP strain sensor with fixtures at two ends.

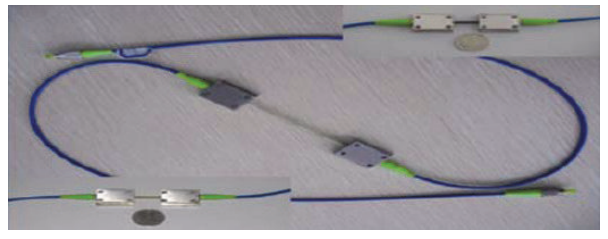

FIGURE 11: Surface-welded FRP strain sensor.

\section{FRP-Packaged Fiber Bragg Grating (FBG) Strain Sensors}

4.1. Package Structure of FRP-Packaged FBG Strain Sensor. Based on research achievements on the FRP-OFBG bars (Figures 20 and 21), a series of embedded FRP-packaged fiber Bragg grating strain sensors, FRP-packaged fiber Bragg grating strain sensors with expanding ends, surface-welding FRP-packaged fiber Bragg grating strain sensors, long gauge embedded FRP-packaged fiber Bragg grating strain sensors, and 3D FRP-packaged fiber Bragg grating strain sensors were developed for the demand of engineering test, shown as Figures 9-13. 


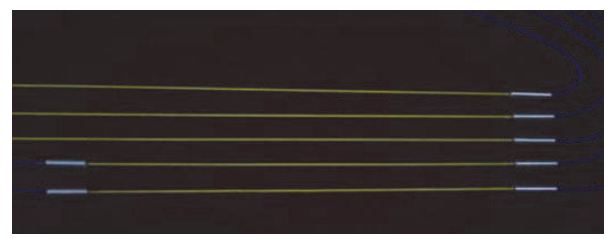

FIGURE 12: Long gauge embeddable FRP strain sensor.

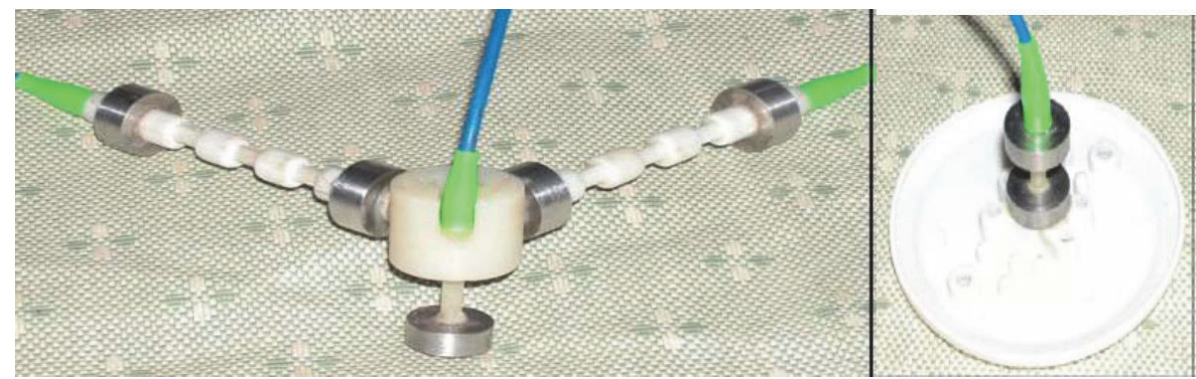

FIGURE 13: Three-dimensional FBG-packaged strain sensor.

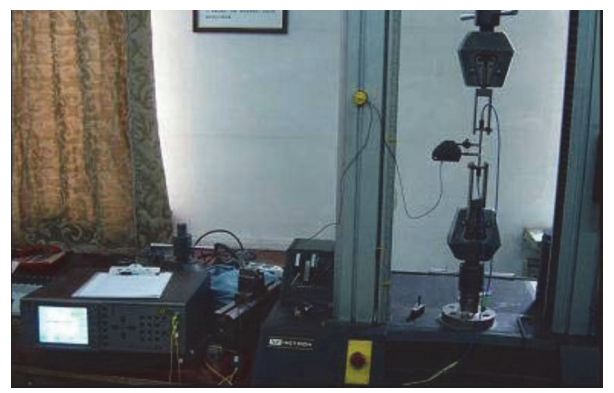

FIGURE 14: Test of FRP-packaged FBG strain sensor.

4.2. Sensing Performance of FRP-Packaged Fiber Grating Strain Sensors. Sensing performance tests in the presented study were conducted on the material testing machine Instron-5569, and the center wavelength of fiber Bragg grating was demodulated by SI-720 produced by MOI company with accuracy of $1 \mathrm{pm}$. Strain of FRP-packaged fiber grating strain sensors was measured by the extensometer, with the resolution of $1 \mu \varepsilon$. In order to eliminate the effect on the variation of center wavelength of temperature, laboratory temperature was maintained as constant at $25^{\circ} \mathrm{C}$ by air conditioning. The test setup is shown in Figure 14. 3 5 loading-unloading cycles were conducted on each type of sensor mentioned earlier, and their variation was recorded in center wavelength and strain, respectively, for analyzing the sensing performance index, shown as Figure 15.

It is shown that, from the test results, the measurement scale of this series of FRP-packaged fiber grating strain sensors is more than $5000 \mu \varepsilon$ (the maximum strain can reach $12000 \mu \varepsilon$ ), the test accuracy is $1 \mu \varepsilon$, the repeatability is less than $1.0 \%$, linearity is less than $1.0 \%$, and hysteresis is less than $0.5 \%$.

\subsection{Sensing Performance of FRP-Packaged Fiber \\ Grating Strain Sensors in Harsh Environment}

4.3.1. Strain Sensing Performance in High-Temperature Environments. The service temperature ranged from $-40^{\circ} \mathrm{C}$ to $60^{\circ} \mathrm{C}$ for most civil engineering structures, but higher temperature occurs in some structural elements; therefore, it is meaningful to research the sensing performance of FRPpackaged fiber grating strain sensors under high-temperature conditions, due to the undesirable high temperature performance of FRP material.

This experiment was conducted on the MTS testing machine, as shown in Figure 14. Strain and variation of center wavelength were measured by the high-temperature extensometer and SI-720 optical fiber grating demodulator produced by MOI company, and the test setup is shown in 


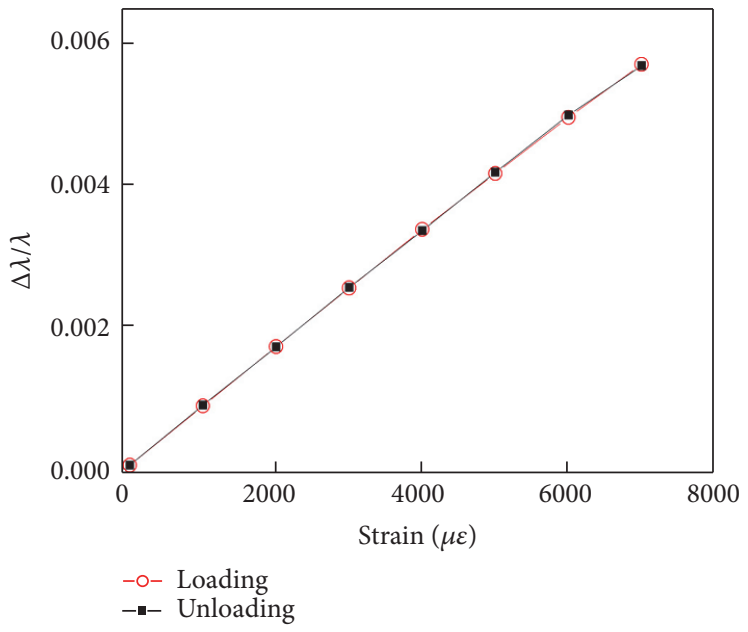

(a) Direct embedded GFRP-packaged FBG sensors

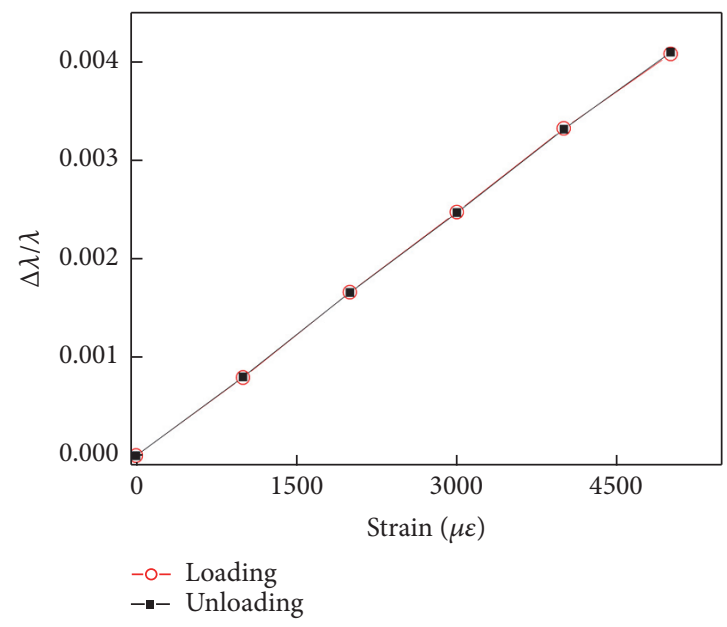

(c) GFRP-packaged FBG sensors with expanding ends

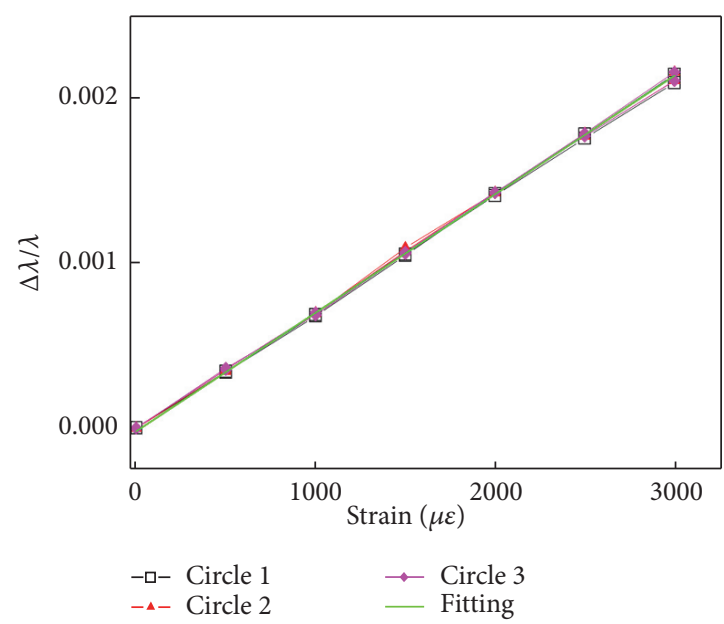

(e) Long gauge embedded GFRP-packaged FBG sensors

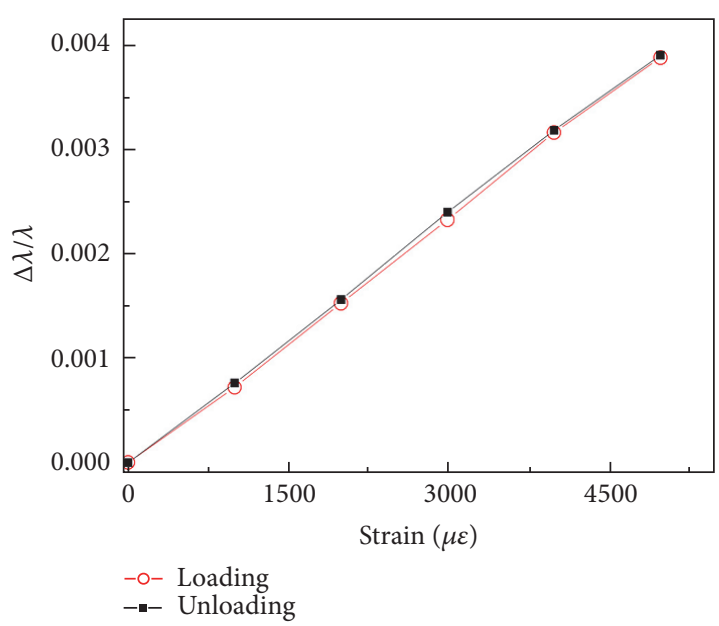

(b) Direct embedded CFRP-packaged FBG sensors

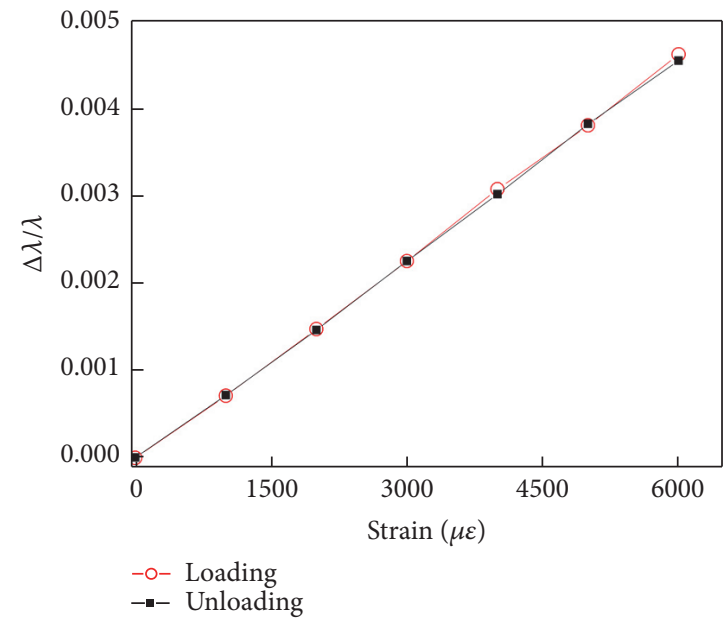

(d) Surface-welding GFRP-packaged FBG sensors

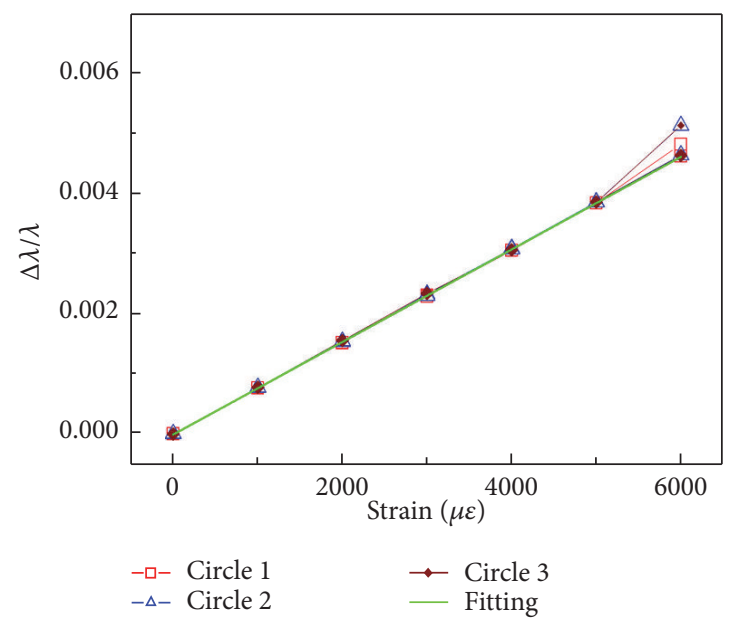

(f) Long gauge embedded GFRP-packaged FBG sensors

FIGURE 15: Properties of the FRP-packaged FBG strain sensors. 

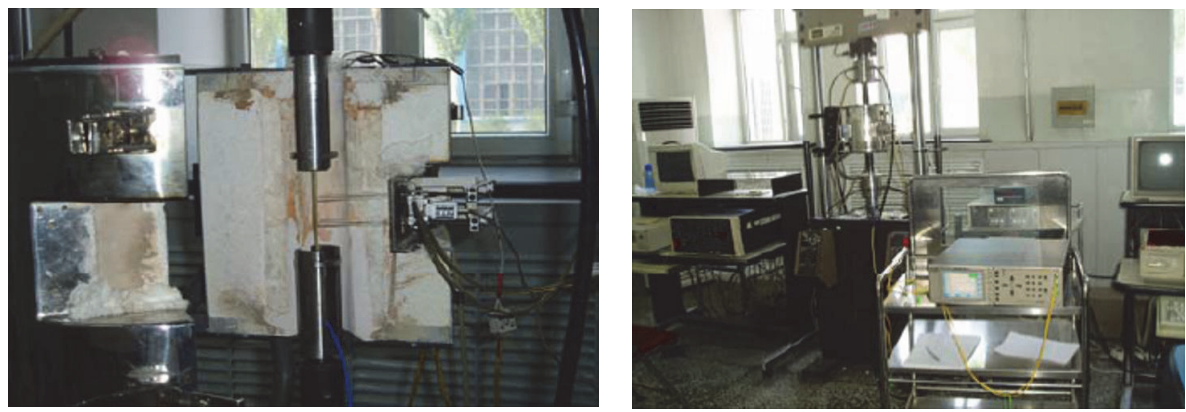

FIGURE 16: Test setup of GFRP-packaged FBG at high temperature.

Figure 16. In the presented experiment, the sensing performances, such as linearity and repeatability, at $20^{\circ} \mathrm{C}, 40^{\circ} \mathrm{C}$, $60^{\circ} \mathrm{C}, 80^{\circ} \mathrm{C}, 100^{\circ} \mathrm{C}, 120^{\circ} \mathrm{C}$, and $140^{\circ} \mathrm{C}$, which were controlled by the high-temperature furnace, were investigated. Experiment results for one of the testing specimens are shown in Figure 17.

It can be seen from the experimental results that the strain sensitivity of the GFRP-packaged FBG sensors at $40^{\circ} \mathrm{C}$, $60^{\circ} \mathrm{C}, 80^{\circ} \mathrm{C}, 100^{\circ} \mathrm{C}, 120^{\circ} \mathrm{C}$, and $140^{\circ} \mathrm{C}$ is around $1.2 \mathrm{pm} / \mu \varepsilon$, being close to that at $20^{\circ} \mathrm{C}$ normal environment. Therefore, we can conclude that the performance of FRP-packaged optical fiber strain sensors does not degenerate under the ambient temperature of $140^{\circ} \mathrm{C}$.

\subsubsection{Fatigue Performance Experiment of FRP-Packaged Opti-} cal Fiber Strain Sensors. In order to examine the stability and reliability of FRP-packaged optical fiber strain sensors applied on the long-term monitoring of civil engineering structures, fatigue performance experiment of this series of FRP-packaged optical fiber strain sensors was performed on the fatigue testing machine MTS-810, with the test frequency selected as $50 \mathrm{~Hz}$. For the purpose of accelerating the fatigue test, the strain amplitude was determined as $2000 \pm 1000 \mu \varepsilon$ and $3000 \pm 1000 \mu \varepsilon$. The center wavelength response of FBG sensors was recorded at intervals of a fixed time in order to compare variation of that at each moment. A significant change of the center wavelength variation at a moment with a comparison to that at the initial moment infers that the fatigue damage is accumulated in the FRP-packaged optical fiber strain sensors, and this phenomenon could be employed to evaluate fatigue reliability of FRP-packaged optical fiber strain sensors. In this paper, two surface-welding GFRP-packaged optical fiber strain sensors and a direct embedded CFRP-packaged optical fiber strain sensor were randomly selected as testing specimens to investigate the sensing performance after high-cycle fatigue; besides, three GFRP-packaged optical fiber strain sensors with expanding ends were also randomly chosen to examine the sensing performance after low-cycle fatigue. During the experiment, the center wavelengths of FBG sensors were recorded by SI425 optical fiber grating demodulator produced by Micron Optics company, in which the instrument wavelength resolution is $5 \mathrm{pm}$ and scanning frequency is $250 \mathrm{~Hz}$. The fatigue test
TABLE 2: The testing results at low cycle fatigue.

\begin{tabular}{lccc}
\hline Specimen & $\begin{array}{c}\text { Strain } \\
\text { amplitude }(\mu \varepsilon)\end{array}$ & $\begin{array}{c}\text { Cycles } \\
(10000 \text { times })\end{array}$ & $\begin{array}{c}\text { Wavelength } \\
\text { variation }(\mathrm{nm})\end{array}$ \\
\hline $\begin{array}{l}\text { Surface welding } \\
\text { GFRP (1) }\end{array}$ & $2000 \sim 3000$ & 100 & 7 \\
$\begin{array}{l}\text { Surface welding } \\
\text { GFRP (2) }\end{array}$ & $2000 \sim 3000$ & 100 & 9 \\
$\begin{array}{l}\text { Surface welding } \\
\text { GFRP (2) }\end{array}$ & $2000 \sim 4000$ & 160 & 6 \\
$\begin{array}{l}\text { Direct embedded } \\
\text { CFRP }\end{array}$ & $2000 \sim 3000$ & 100 & 7 \\
\hline
\end{tabular}

setup is shown in Figure 18. Part of the experiment results of all the specimens are summarized in Table 2. Figure 19 shows segmenting time history curves of one specimen.

We can see from experimental results that there is no strain decrease of FRP-packaged FBG strain sensors during the fatigue test and that no member resistance reduction and no obvious damage occurred during the test. After multiple fatigue cycles, none of the significant drifts of the fiber grating center wavelength appeared. It is shown that FRP composites protect the sensing element effectively, and the stability of FRP-packaged FBG strain sensors kept excellent, which is suited for civil engineering applications.

Moreover, the fatigue tests of FRP-packaged FBG strain sensors at high strain amplitude were conducted, and a comparison was made between the sensors' strain sensing performance after certain fatigue circles and that of the control group. In this test, the strain amplitude of sensor 1 is $3000 \pm 2000 \mu \varepsilon$ and that of sensor 2 is $4500 \pm 1500 \mu \varepsilon$; test results are shown in Figures 20(a)-20(d).

It can be seen that FRP-packaged strain sensors, which have experienced a certain number of fatigue cycles, retain the original strain sensing performance, such as good linearity and repeatability, as well as a longer fatigue life.

\subsubsection{Corrosion Durability Test of FRP-Packaged Optical Fiber} Bragg Grating Strain Sensors. In order to verify the sensor's durability index, different types of FRP-packaged optical fiber Bragg grating (FBG) strain sensors were placed in salt spray chamber, with the working temperature of $35^{\circ} \mathrm{C}$ and the salt 

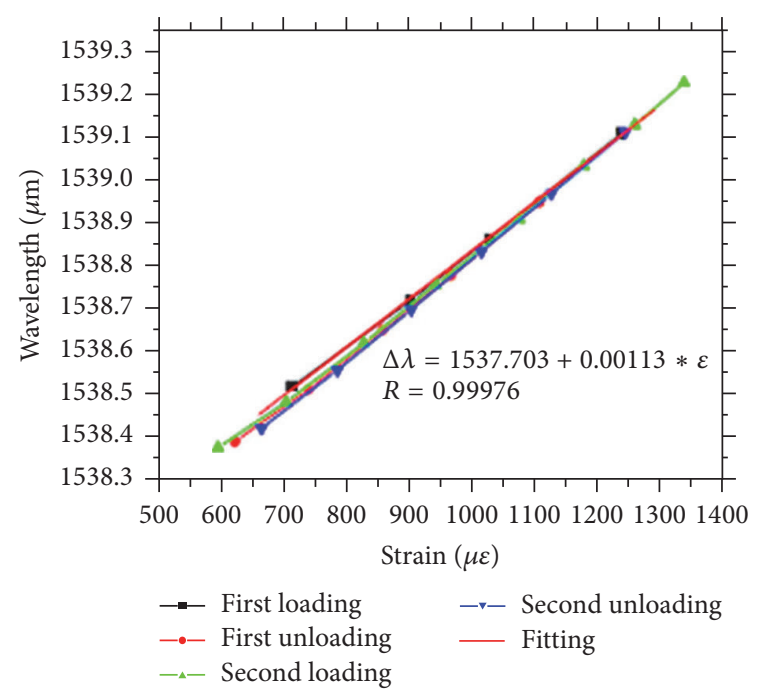

(a) $20^{\circ} \mathrm{C}$

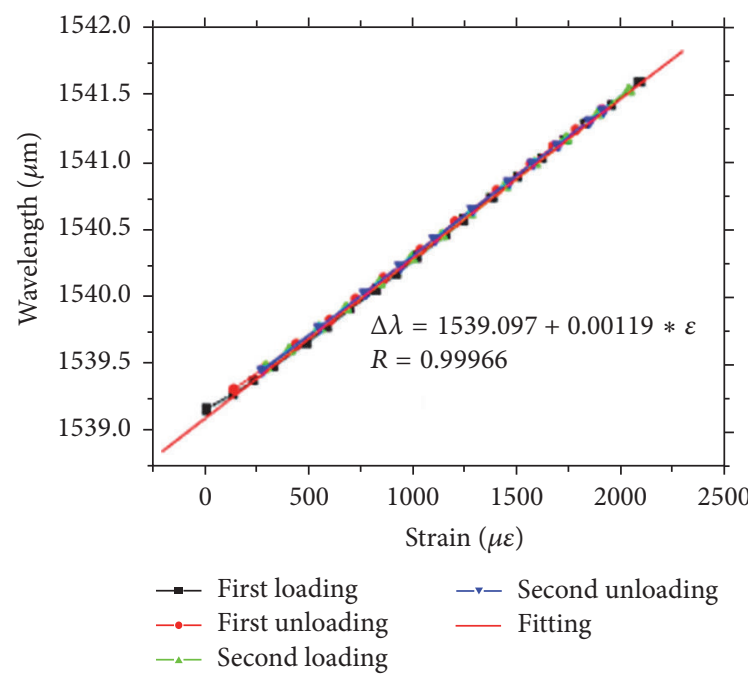

(c) $80^{\circ} \mathrm{C}$

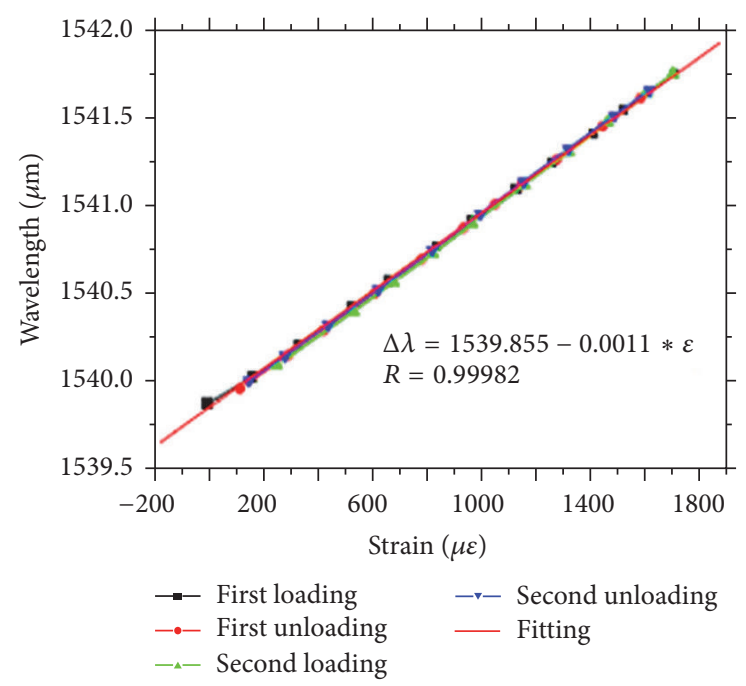

(e) $120^{\circ} \mathrm{C}$
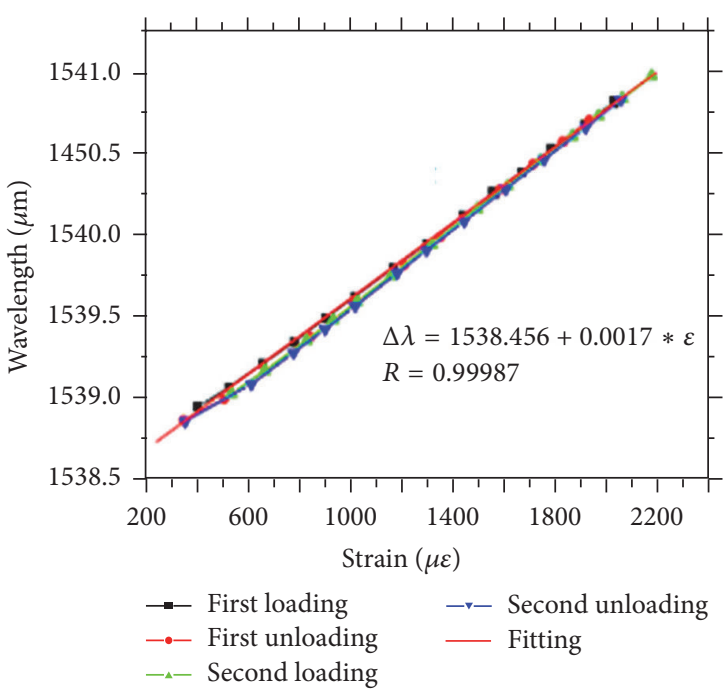

(b) $60^{\circ} \mathrm{C}$

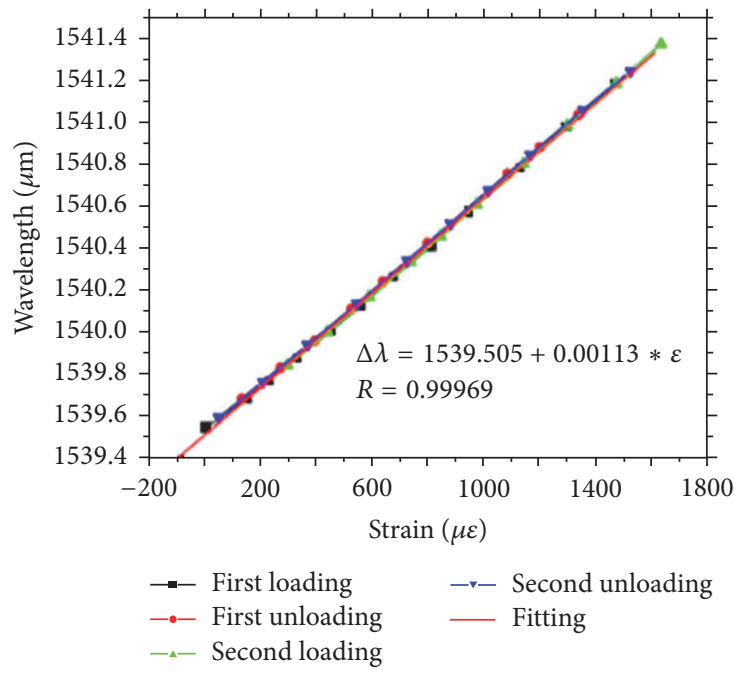

(d) $100^{\circ} \mathrm{C}$

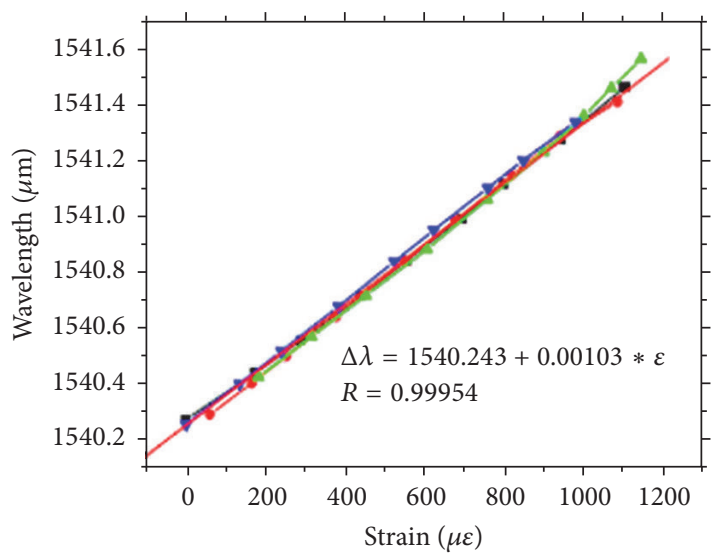

$\quad--$ First loading $\quad-\checkmark-$ Second unloading
$-\bullet-$ First unloading $\quad$ - Fitting
$-\Delta-$ Second loading

(f) $140^{\circ} \mathrm{C}$

FIGURE 17: Relationship between wavelength changes and strain at different temperatures of sensor one. 

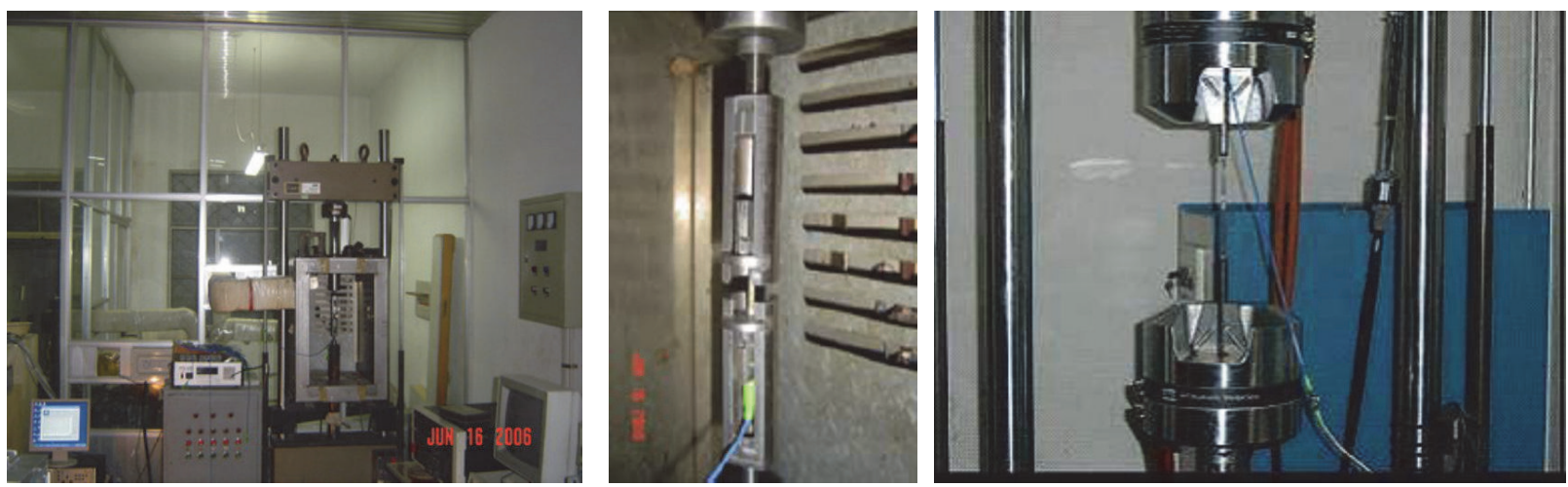

FIGURE 18: Fatigue test of FRP-packaged FBG strain sensor.

TABLE 3: Monitoring items and technical parameters of FRP-packaged optical fiber Bragg grating sensors.

\begin{tabular}{|c|c|c|c|c|c|c|}
\hline \multirow{2}{*}{ Object } & \multirow{2}{*}{ Monitoring items } & \multicolumn{4}{|c|}{ Sensors } & \multirow{2}{*}{ Numbers } \\
\hline & & Method & Frequency & Accuracy & Scale & \\
\hline Main-beam & Steel strain & FBG & $20 \mathrm{~Hz}$ & $1 \mu \varepsilon$ & $\pm 1000 \mu \varepsilon$ & 40 \\
\hline Main-beam & Steel temperature & FBG & 1 time/h & $0.5^{\circ} \mathrm{C}$ & $-20^{\circ} \mathrm{C} \sim+70^{\circ} \mathrm{C}$ & 15 \\
\hline Main-tower & Concrete strain & FBG & $20 \mathrm{~Hz}$ & $1 \mu \varepsilon$ & $\pm 1000 \mu \varepsilon$ & 8 \\
\hline Main-tower & Concrete temperature & FBG & 1 time/h & $0.5^{\circ} \mathrm{C}$ & $-20^{\circ} \mathrm{C} \sim+70^{\circ} \mathrm{C}$ & 8 \\
\hline
\end{tabular}

spray of $3.5 \% \mathrm{NaCl}$ solution, shown as Figure 21. It can be seen from the results of corrosion test that the corrosion resistance of the metal packaged FBG sensors is far less than the FRP-packaged FBG sensors. This series of FRP-packaged FBG strain sensors overcomes the insurmountable durability issues compared with the traditional adhesive packaged FBG strain sensors, possessing outstanding advantages, such as simple laying process in practical engineering, large measurement scale (more than $5000 \mu \varepsilon$; the maximum can reach $10000 \mu \varepsilon)$, excellent durability, high accuracy $(1 \sim 2 \mu \varepsilon)$, and low error correction factor. Furthermore, it can be easily customized according to custom.

Key performance indicators of the series of FRP-packaged optical fiber Bragg grating strain sensors are summarized as follows: measurement scale is more than $5000 \mu \varepsilon$, test accuracy is $1 \mu \varepsilon$, repeatability is less than $1 \%$, linearity is less than $1.0 \%$, hysteresis is less than $0.5 \%$, and so forth. No fatigue properties are found under more than one million times of fatigue cycles, with strain amplitude of $3000 \pm 1000 \mu \varepsilon$.

This series of FRP-packaged FBG strain sensors is particularly suitable for the internal strain measurement of the concrete structures, besides the whole-process monitoring of civil engineering structures, including construction stage, completion test stage, and in-service stage. Still, it also can be easily used for road engineering, geotechnical engineering, and so forth throughout the reconstruction design.

\section{Applications in Aizhai Bridge}

Aizhai Bridge is a super long suspension bridge with separated towers and beams and with span arrangement of $242 \mathrm{~m}$
$+1176 \mathrm{~m}+116 \mathrm{~m}$. In order to obtain the information on structure behavior in service, a structural health monitoring (SHM) system was established for providing information about conditions such as strain, temperature, acceleration, deflection, wind velocity, cable force, and humidity. In this SHM system, surface-welding GFRP-packaged optical fiber strain and temperature sensors (shown as Figure 9) are used for strain and temperature measuring of the main beam and main tower, and the measuring point arrangement is shown in Figure 22. The monitoring items and technical parameters of FRP-packaged optical fiber Bragg grating sensors are listed in Table 3. The data, acquired and processed by FBG demodulator, is transferred to the data receiving server, in which the data can be retained, managed, and arithmetically processed.

\section{Conclusions}

In this study, a series of FRP-packaged optical fiber Bragg grating strain sensors to completely meet the requirements of the rough civil engineering infrastructures are introduced, and their sensing performances under normal environment and harsh environment are experimentally investigated; the following conclusions can be drawn:

(1) Based on stain transfer mechanism, it is theoretically proved that the testing accuracy of FRP-packaged optical fiber strain sensors is sufficient for civil engineering structures and can be applied in the practical structures directly without any error correction. 


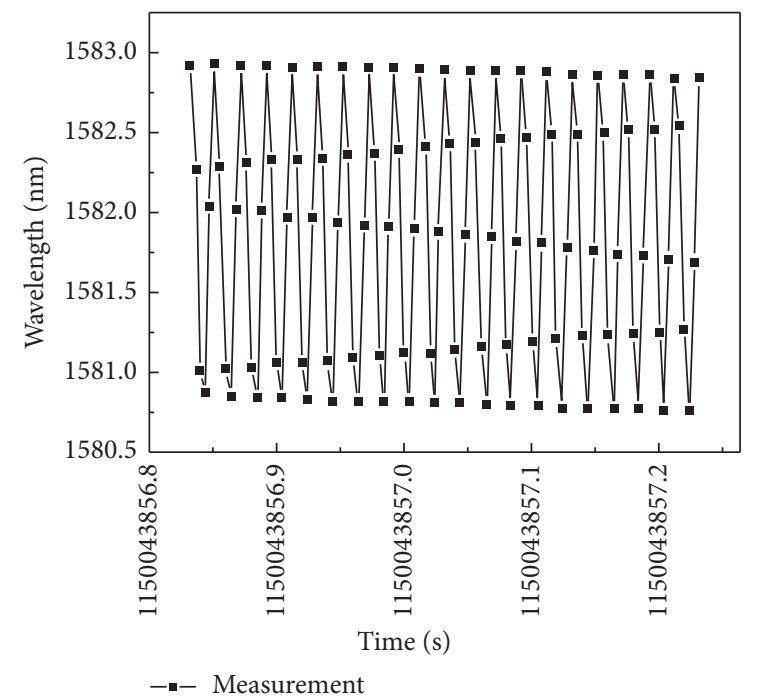

(a) $22: 47$

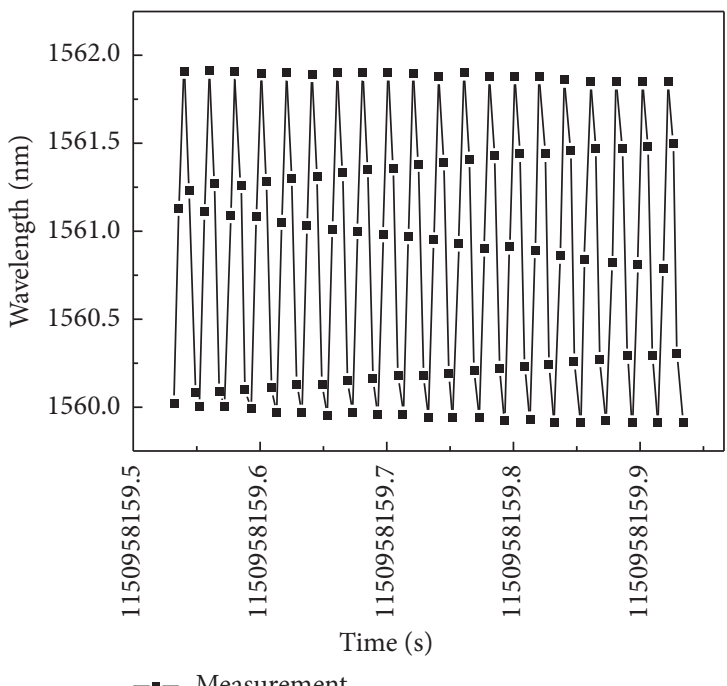

(c) $2: 45$

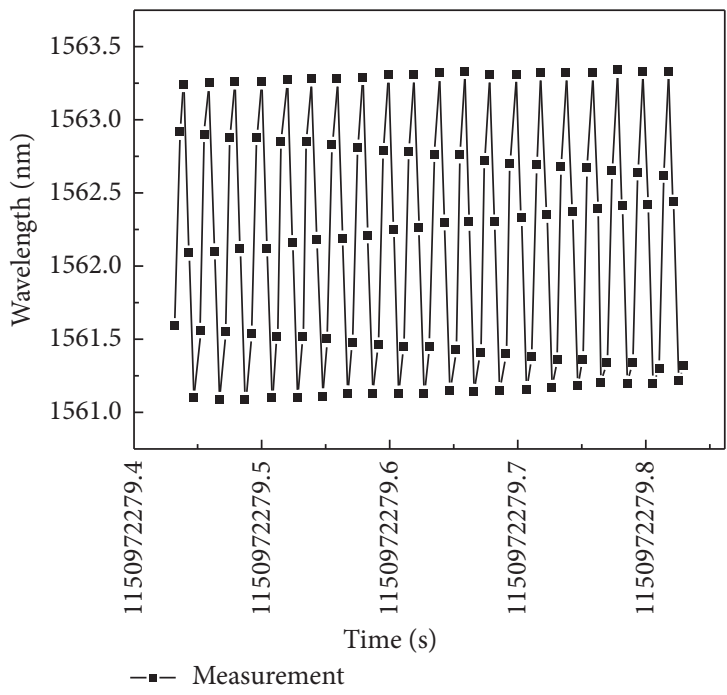

(e) $6: 40$

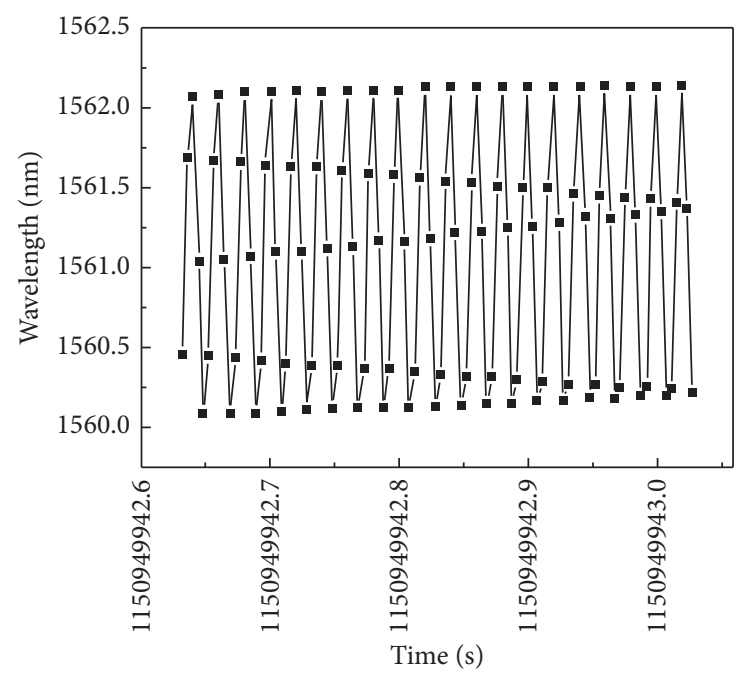

--- Measurement

(b) $0: 28$

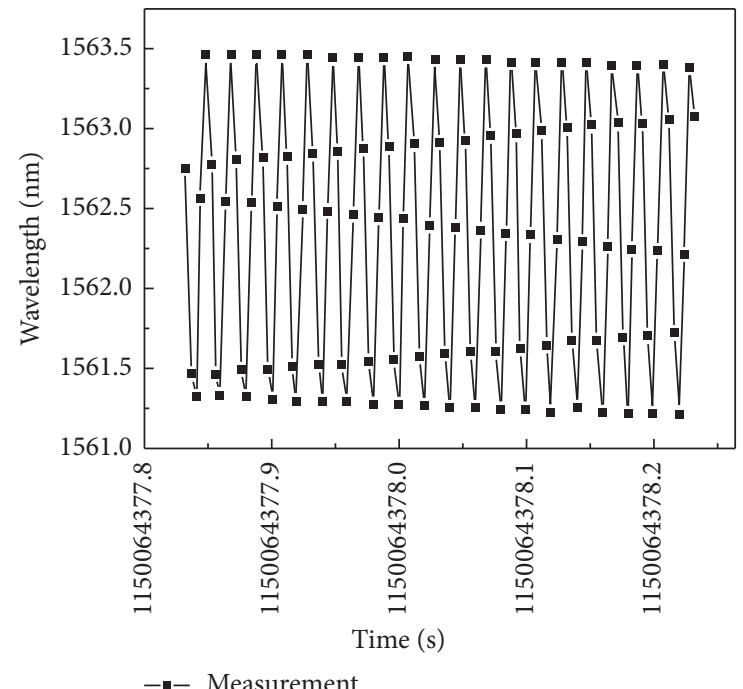

(d) 4:29

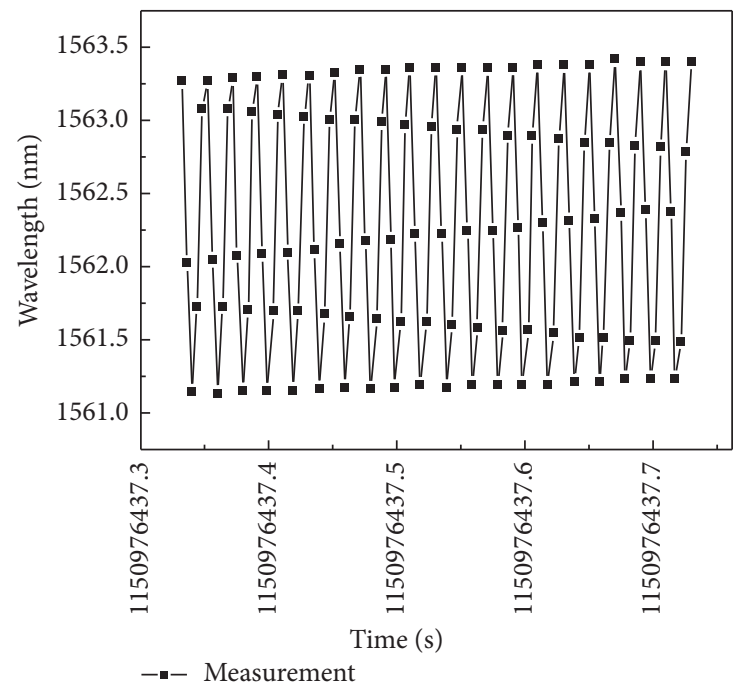

(f) $7: 53$

FIGURE 19: Response of the FBG wavelength at different times. 


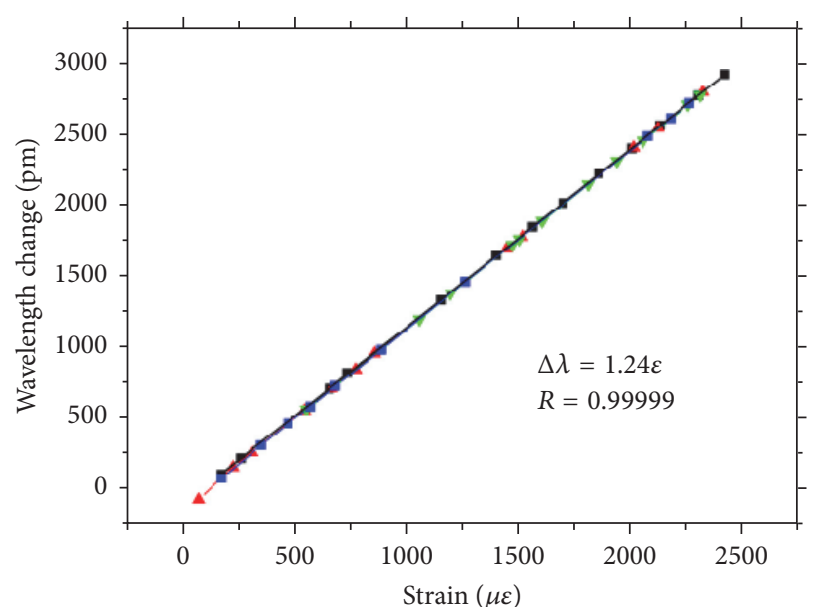

- - The first circle loading

- $\_$- The first circle unloading

$-\nabla-$ The second circle loading

- - The second circle unloading

_ Fitting

(a)

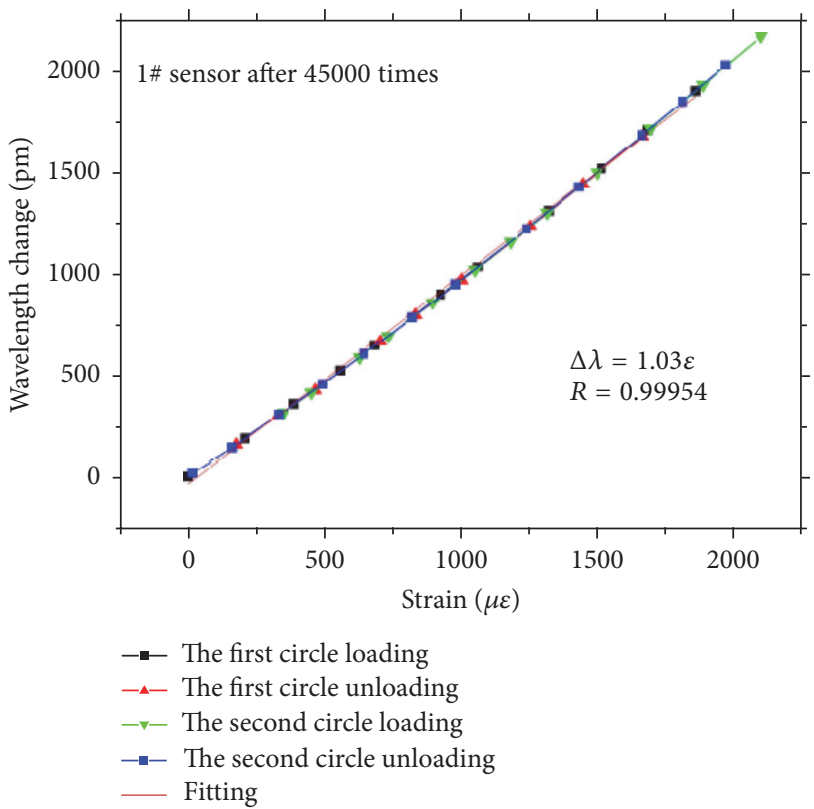

(c)

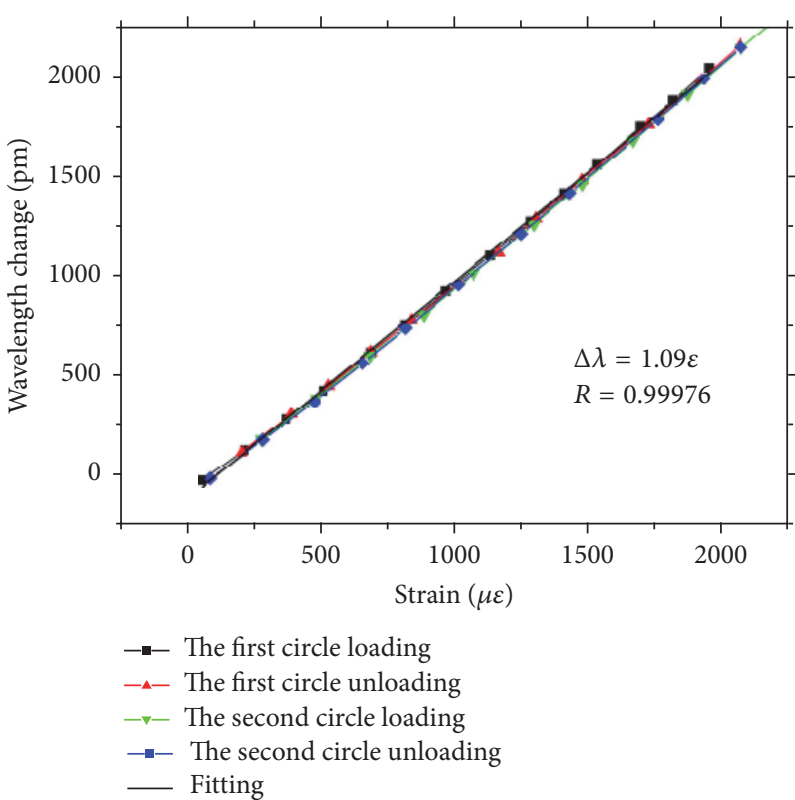

(b)

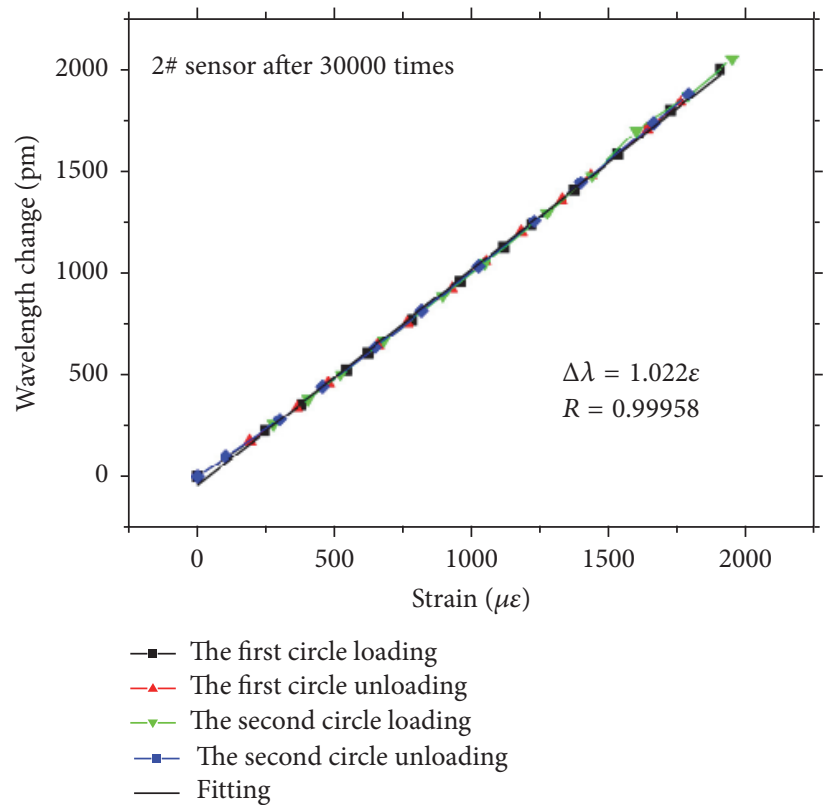

(d)

FIGURE 20: In situ diagram of FRP-packaged OFBG sensors installation.

(2) FRP composites do not change the sensing performance of the FBG sensor; furthermore, the measurement scale significantly increased to $8000 \sim 12000 \mu \varepsilon$.

(3) FRP-packaged optical fiber FBG strain sensors do not degenerate under the ambient temperature of $140^{\circ} \mathrm{C}$ and maintain excellent linearity and repeatability as the bare FBG in the case of experiencing a certain number of fatigue cycles. Besides, they have superior corrosion resistance compared with metal packaged optical fiber strain sensors, which makes them particularly suitable for the internal strain measurement of the concrete structures and the whole-process monitoring for civil engineering structures, including construction stage, completion test stage, and inservice stage.

\section{Competing Interests}

The authors declare that they have no financial and personal relationships with other people or organizations that can inappropriately influence this work and that there is no professional or other personal interest of any nature or 


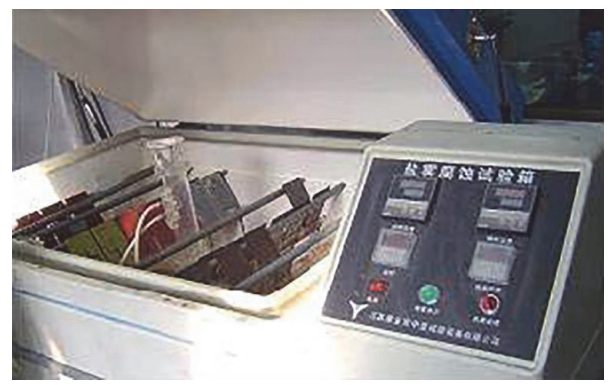

FIGURE 21: Schematic diagram of FRP-packaged OFBG sensors installation.

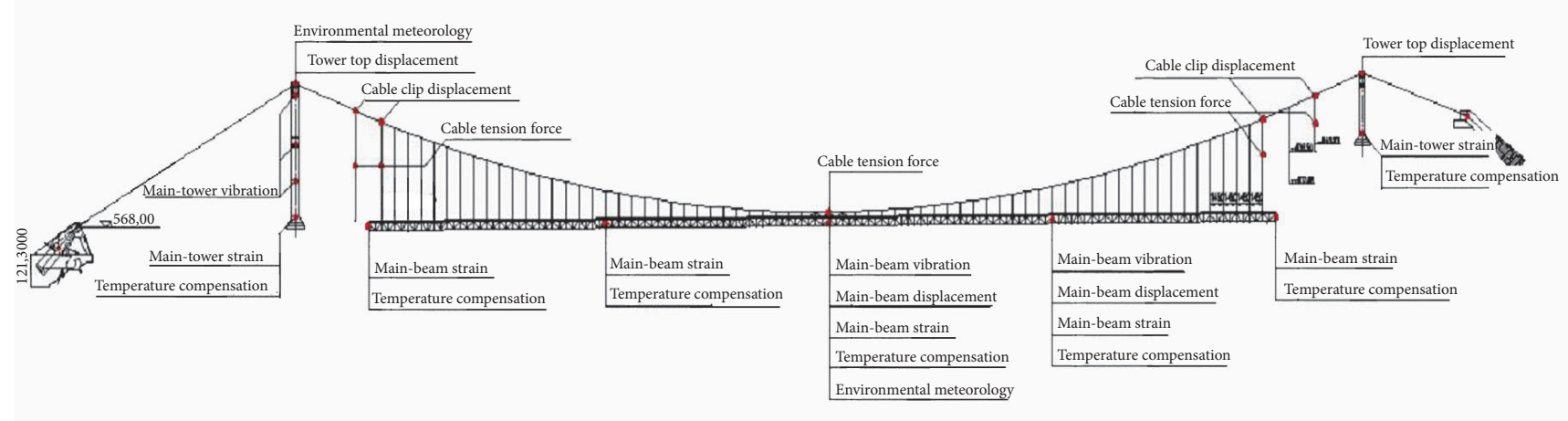

FIGURE 22: Measuring point arrangement of all kinds of sensors.

kind in any product, service, and/or company that could be construed as influencing the position presented in or the review of the manuscript.

\section{References}

[1] J. P. Ou, "Damage accumulation and safety evaluation for important large infrastructures," in 21st Century's Chinese Mechanics-9th Science Association Reports of 'Forum for Youth Scientist', pp. 179-189, Tsinghua University Press, Beijing, China, 1996.

[2] G. W. Housner, L. A. Bergman, T. K. Caughey et al., "Structural control: past, present, and future," Journal of Engineering Mechanics, vol. 123, no. 9, pp. 897-971, 1997.

[3] G. Meltz, W. Morey, and W. Glenn, "Formation of bragg gratings in optical fibers by a transverse holographic method," Optics Letters, vol. 14, no. 15, pp. 823-825, 1989.

[4] A. A. Mufti, "FRPs and FOSs lead to innovation in Canadian civil engineering structures," Construction and Building Materials, vol. 17, no. 6-7, pp. 379-387, 2003.

[5] Z. Zhou, T. Graver, and J. P. Ou, “Techniques of advanced FBG sensors: manufacturing, demodulation, encapsulation and their application in the structural health monitoring of bridges," Pacific Science Review, vol. 5, no. 1, pp. 116-121, 2003.

[6] Z. Zhou, B. Wang, and J. P. Ou, "Local damage detection of RC structures with distributive FRP-OFBG sensors," in Proceedings of the 2nd International Workshop on Structural Health Monitoring of Innovative Civil Engineering Structures, vol. 22-23, pp. 205-214, Winnipeg, Canada, September 2004.

[7] Z. Zhou and J. P. Ou, "Development of FBG sensors for Structural Health Monitoring in civil infrastructures," in Proceeding of the North American Euro-Pacific Workshop 'Sensing Issues in Civil Structural Health Monitoring', Waikiki, Hawaii, USA, 2004.

[8] Z. Zhou, C. G. Lan, and J. P. Ou, "A novel ice-pressure sensor based on dual FBGs," in Smart Structures and Materials 2005: Sensors and Smart Structures Technologies for Civil, Mechanical, and Aerospace Systems, vol. 5765 of Proceedings of SPIE, San Diego, Calif, USA, 2005.

[9] Z. Zhou, J. Liu, H. Li, and J. Ou, "A new kind of high durable traffic weighbridge based on FBG sensors," in 17th International Conference on Optical Fibre Sensors, vol. 5855 of Proceedings of SPIE, pp. 735-738, Bruges, Belgium, May 2005.

[10] J. P. Ou and Z. Zhou, “Techniques of optical fiber Bragg grating smart sensors and intelligent monitoring systems of infrastructures," in Proceedings of the 1st International Workshop on Advanced Smart Materials and Smart Structures Technology, p. 23, Honolulu, Hawaii, USA, June 2003.

[11] Z. Zhou, J. P. Ou, and B. Wang, "Smart FRP-OFGB bars and their application in reinforced concrete beams," in Proceedings of the 1st International Conference on Structural Health Monitoring and Intelligent Structure, vol. 13-15, pp. 861-866, Tokyo, Japan, November 2003.

[12] H. Tsutsui, A. Kawamata, T. Sanda, and N. Takeda, "Detection of impact damage of stiffened composite panels using embedded small-diameter optical fibers," Smart Materials and Structures, vol. 13, no. 6, pp. 1284-1290, 2004.

[13] C.-Y. Ryu, J.-R. Lee, C.-G. Kim, and C.-S. Hong, "Buckling behavior monitoring of a composite wing box using multiplexed and multi-channeled built-in fiber Bragg grating strain sensors," NDT \& E International, vol. 41, no. 7, pp. 534-543, 2008.

[14] S.-I. Takeda, Y. Aoki, and Y. Nagao, "Damage monitoring of CFRP stiffened panels under compressive load using FBG sensors," Composite Structures, vol. 94, no. 3, pp. 813-819, 2012. 
[15] K. I. Tserpes, V. Karachalios, I. Giannopoulos, V. Prentzias, and R. Ruzek, "Strain and damage monitoring in CFRP fuselage panels using fiber Bragg grating sensors. Part I: design, manufacturing and impact testing," Composite Structures, vol. 107, pp. 726-736, 2014.

[16] T. C. Triantafillou, "Shear strengthening of reinforced concrete beams using epoxy-bonded FRP composites," ACI Structural Journal, vol. 95, no. 2, pp. 107-115, 1998. 


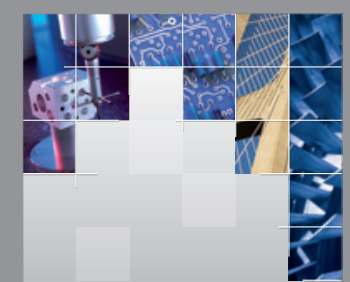

\section{Enfincering}
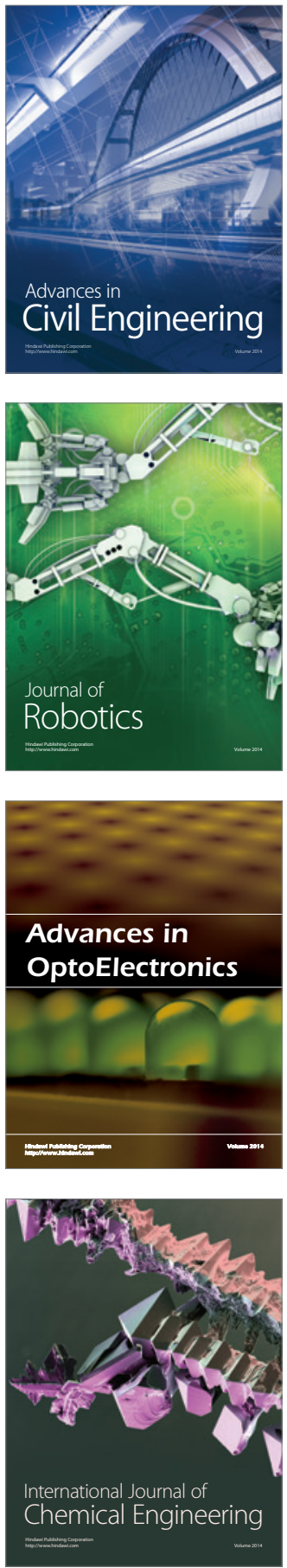

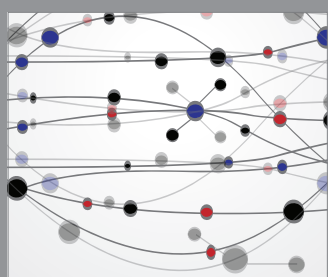

The Scientific World Journal

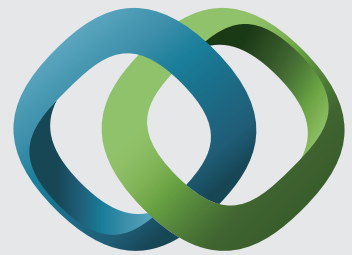

\section{Hindawi}

Submit your manuscripts at

http://www.hindawi.com
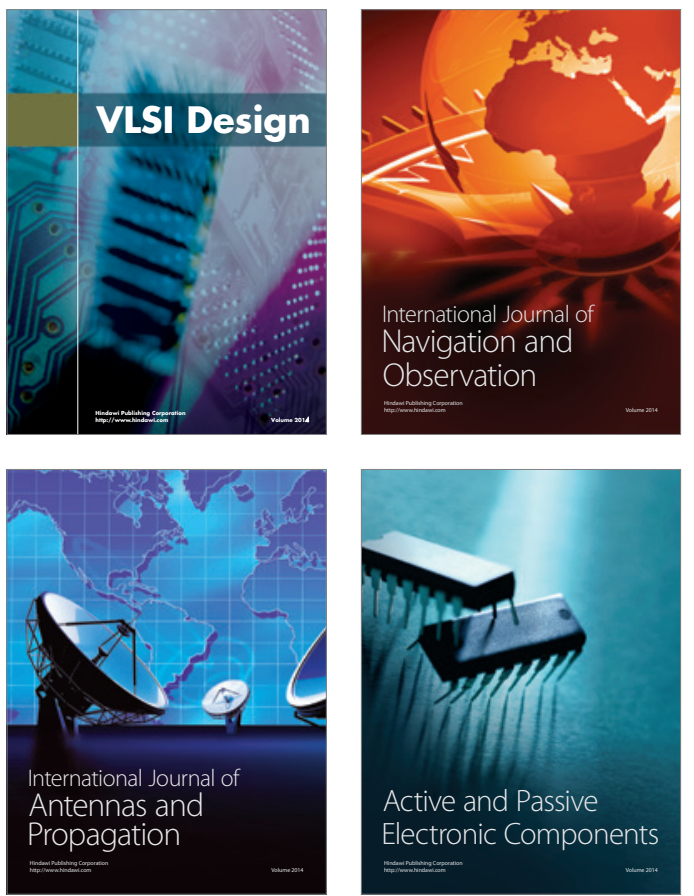
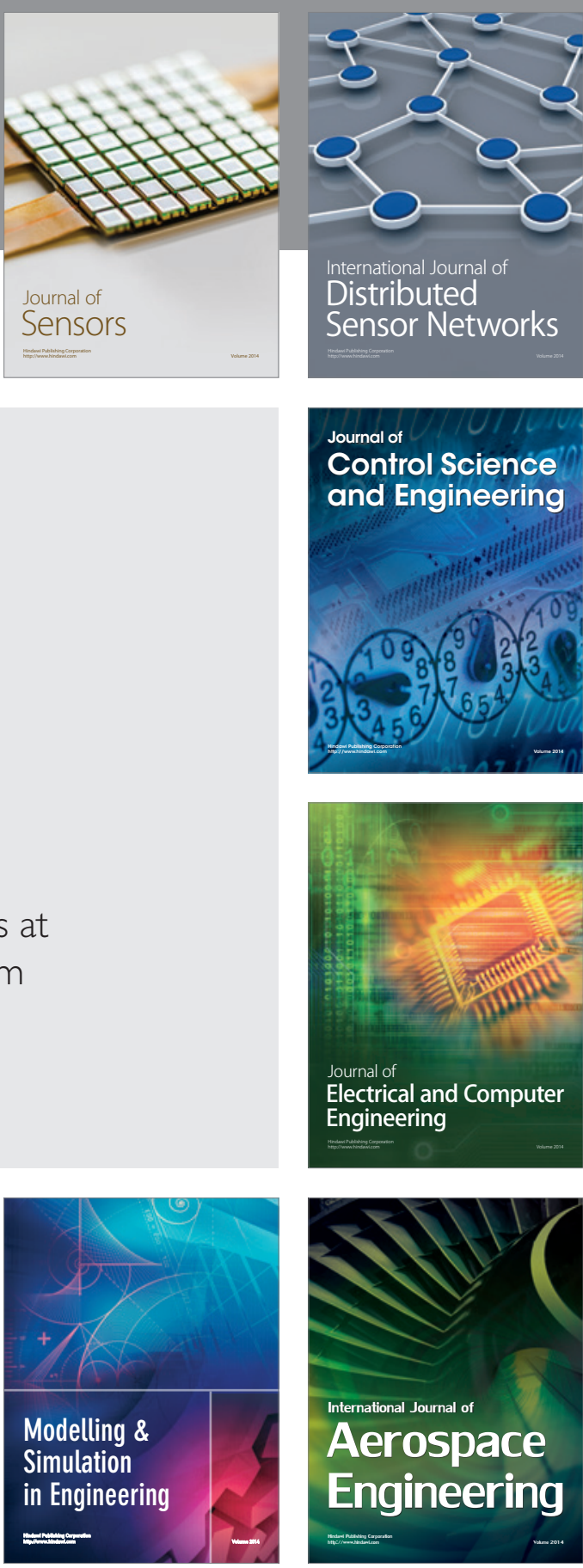

International Journal of

Distributed

Sensor Networks

Journal of

Control Science

and Engineering
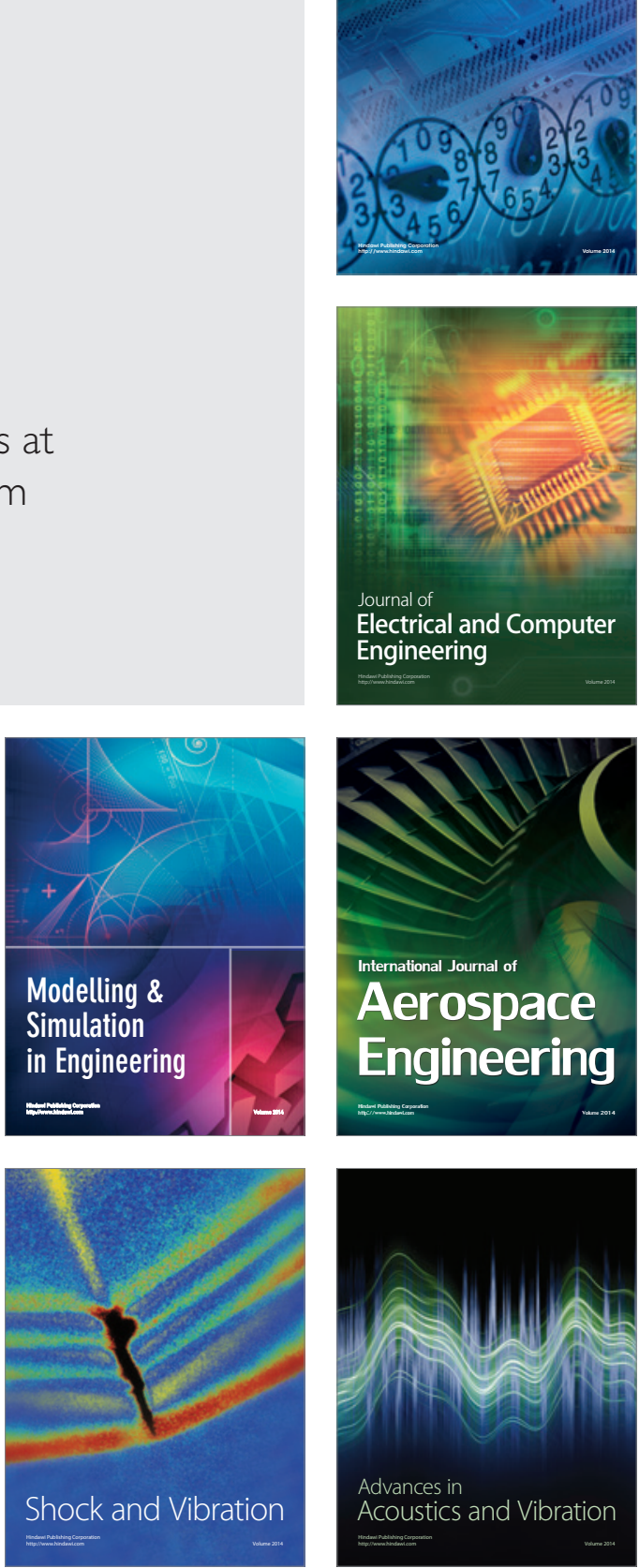